ISSN: 0213-2087 eISSN: 2444-7080

DOI: https://doi.org/10.14201/shhc202139235268

\title{
DE CHICAGO A KENT STATE: UN RETRATO MUSICAL DE LAS PROTESTAS CONTRA LA GUERRA DE VIETNAM
}

\section{From Chicago to Kent State: A Musical Portrait of the Protests against the Vietnam War}

\author{
Juan Andrés GARCÍA MARTÍN \\ Universidad Rey Juan Carlos \\ https://orcid.org/0000-0001-8672-5149
}

Recibido: 10/01/2021 Revisado: 17/03/2021 Aceptado: 30/04/2021

RESUMEN: La participación de Estados Unidos en la guerra de Vietnam generó reacciones de apoyo y rechazo en la sociedad estadounidense. La movilización, en principio dispersa, alcanzó su punto álgido en las protestas acaecidas en la Convención del Partido Demócrata de Chicago en 1968 y en la Universidad de Kent State en 1970. La represión que siguió a estas manifestaciones añadió nuevos argumentos a unas protestas que ya no solo denunciaban la participación en el conflicto sino la restricción de libertades. Todos estos acontecimientos generaron una abundante producción musical por parte de diversos cantautores en forma de canciones de protesta.

A través de un análisis de los contenidos líricos de estas composiciones, este artículo analiza el retrato musical de estas protestas y de la posterior represión. Ello permitirá determinar las preferencias temáticas y clasificar las canciones de acuerdo con esta categorización, así como concretar las cuestiones objeto de denuncia. De este modo, podremos vislumbrar el posicionamiento de los compositores y la descripción de la situación que atravesaba el país.

Palabras clave: Guerra de Vietnam; movilización; música; canción protesta; Chicago; Kent State; represión. 


\section{JUAN ANDRÉS GARCÍA MARTÍN \\ DE CHICAGO A KENT STATE: UN RETRATO MUSICAL DE LAS PROTESTAS CONTRA LA GUERRA DE VIETNAM}

ABSTRACT: American participation in the Vietnam War provoked several reactions of support and rejection among American society. The mobilization against this war reached its peak through several rallies such as the 1968 National Democratic Convention in Chicago or the Kent State University protests and shootings in 1970. The following repression added new arguments to protests that not only denounced the military escalation but the limitation of liberties. All these actions inspired an enormous musical production by singer-songwriters who wrote protest songs.

Through the analysis of the lyrical contents of these compositions, this paper studies the musical portrait of these protests and the following repression. This will allow us to determine the thematic preferences and classify the songs according to this categorization, as well as establish the matters that these singer-songwriters denounced. Finally, we will be able to identify the positioning of these composers and their description of the conditions of the country.

Key words: Vietnam War; students; music; protest-song; Chicago; Kent State; repression.

\section{Planteamiento de la investigación: objetivos y metodología}

El presente texto estudia el impacto de la movilización contra la Guerra de Vietnam en la música de protesta estadounidense. Para ello, este artículo toma como punto de análisis los acontecimientos y protestas antibélicas acaecidas durante el trienio comprendido entre 1968 y 1970, ya que fueron los momentos de mayor intensidad en la oposición a la guerra. A pesar de esta propuesta cronológica, esta investigación contará con cierta flexibilidad en los márgenes temporales. Ello permitirá observar la evolución de estas protestas y su retrato musical con anterioridad y posterioridad a las fechas señaladas, en aras de comprender dicha movilización en su totalidad.

Para llevar a cabo esta propuesta, tendremos en cuenta el análisis realizado por Alan P. Merriam quien, en su obra The Anthropology of Music, dedicó un amplio capítulo a diferenciar los usos y funciones de la música, de las cuales, varias se agrupan en la canción protesta estadounidense ${ }^{1}$. En base a estos presupuestos,

1. Además de servir como medio de expresión emocional, comunicación y de entretenimiento, la canción de protesta contiene una función de refuerzo del cumplimiento de las normas sociales, ya que denuncia la intervención estadounidense en Vietnam, pero también el autoritarismo y la represión de los gobiernos del país hacia las movilizaciones antibélicas. En tal sentido, esta música también adquiere una función de representación simbólica de ideas y comportamientos, tales como el antibelicismo o las movilizaciones contrarias al conflicto. Al transmitir los valores del movimiento antibelicista, la canción de protesta contribuye a la continuidad y estabilidad de una cultura. Se trata, por lo tanto, de un vehículo transmisor de la realidad histórica de un momento concreto. Por último, la canción de protesta implica una función integradora de la sociedad al actuar como punto de encuentro en el cual los miembros de aquella se unen para participar en actividades que requieren cooperación y coordinación grupal. Merriam, Alan P.: The Anthropology of Music. Evanston: Northwestern University, 1964, pp. 209-229. 


\section{JUAN ANDRÉS GARCÍA MARTÍN \\ DE CHICAGO A KENT STATE: UN RETRATO MUSICAL DE LAS PROTESTAS \\ CONTRA LA GUERRA DE VIETNAM}

este estudio analizará el contexto en el que se llevaron a cabo las composiciones musicales y su impacto sobre estas últimas, buscando las razones de esta fecundidad compositiva. Igualmente, examinaremos la manera en que la canción de protesta reflejó la realidad que sacudía el país. Todo ello permitirá conocer el posicionamiento de los cantautores ya no solo ante el conflicto, sino ante la movilización antibélica y la posterior represión, lo que en última instancia concretará los valores esgrimidos por estos compositores.

Para llevar a cabo esta tarea, esta investigación se sustenta en la búsqueda, identificación y recopilación de canciones contemporáneas a las movilizaciones antibélicas, prestando especial atención a aquellas que hacen referencia a las protestas acaecidas en Chicago y Kent State en 1968 y 1970 y a la posterior represión sobre los manifestantes. Dado que estas composiciones se hallan encuadradas de manera mayoritaria en el género de música folk y en la categoría de la música de protesta contra la intervención norteamericana en el sudeste asiático, se ha recurrido a la revista Broadside para hallar aquellas canciones y artistas que aluden a la temática indicada. La utilización de esta publicación de música folk fundada en 1962 como altavoz escrito para cantautores se ha completado a través de una criba temática de discografía y con la consulta de bibliografía especializada en la materia. A continuación, se ha realizado un análisis de los contenidos líricos de dicha selección, lo que finalmente ha permitido clasificar y describir dichas composiciones desde un punto de vista temático.

Ahora bien, ¿por qué estudiar el impacto musical de la Guerra de Vietnam y el rechazo generado a través de la canción protesta? Varios historiadores han proporcionado respuesta a esta pregunta. En opinión de Ben Arnold, ningún otro periodo ni conflicto de la historia estadounidense ha producido una cultura de protesta con una cantidad semejante de composiciones ${ }^{2}$. Partiendo de esta base, podemos clasificar la producción científica sobre la cuestión en varias categorías.

En primer lugar, existen aquellas obras que se han aproximado directamente a la música referente al conflicto del sudeste asiático. La monografía escrita por James Perone constituye una excelente aproximación que, al establecer una división entre canciones antibélicas y pro-bélicas descritas en orden cronológico, puede producir una categorización un tanto escueta ${ }^{3}$. La obra formulada por Doug Bradley y Craig Werner analiza el papel de la música entre los combatientes desde la perspectiva de los testimonios personales de aquellos ${ }^{4}$. Por su parte, el estudio

2. ARNOLD, Ben: Music and War. A Research and Information Guide. Nueva York: Garland, 1993, p. 324; Arnold, Ben: "War Music and the American Composer during the Vietnam Era", The Musical Quarterly, 75 (3), 1991, p. 318.

3. A nuestro entender, la investigación de Perone es posiblemente la obra más completa sobre la producción musical en referencia a la Guerra de Vietnam. A pesar de ello, esta obra apenas cuenta con algunas composiciones sobre el objeto de estudio: Ballad of the Two Brothers, G.I. Movement, Mr. Professor y Ohio. Perone, James E.: Songs of the Vietnam Conflict. Westport: Greenwood Press, 2001.

4. En su obra, Bradley y Werner prestan atención a la interacción musical entre veteranos y diferentes grupos de combatientes. Sin embargo, apenas se incluyen un puñado de canciones referentes a 
elaborado por Kevin Hillstrom y Laurie C. Hillstrom aborda temáticamente el conflicto, pero no deja de ser una selección de piezas musicales, literarias y cinematográficas $^{5}$. En una línea similar, Bruce Franklin ha elaborado una obra que incluye tanto una antología de poemas, relatos y textos escritos por veteranos, activistas y periodistas, como una selección de obras musicales sobre el conflicto ${ }^{6}$. También debe ser referenciada la obra de Lee Andresen, quien realiza un análisis próximo a la historia emocional y añade alguna categoría novedosa a las ya elaboradas por los mencionados compañeros de estudio -música elaborada por afroamericanos, música escuchada por los soldados y música posterior al conflicto- ${ }^{7}$. Por último, no debemos olvidar las investigaciones de Ben Arnold, quien supera el enfoque de la música de protesta y se adentra en cómo la música orquestal y sus compositores reflejaron el conflicto ${ }^{8}$.

La historiografía norteamericana ha producido un segundo punto de vista en el que incluimos aquellas investigaciones en forma de selección de las canciones de protesta más representativas. Esta categoría tiene uno de sus ejemplos más nítidos en la obra de Dorian Lynsnkey, quien realiza un interesante pero disperso análisis de varias composiciones que cubren un amplio abanico temático y geográfico a lo largo del siglo xx, incluyendo en él varias piezas musicales antibelicistas referentes al conflicto vietnamita?

A pesar de esta producción, hemos observado que las obras citadas han preferido divisiones sencillas -composiciones pacifistas o probélicas- y cronológicas y han realizado análisis temáticos limitados. Ello ha provocado que varios autores no hayan incluido las protestas antibélicas de Chicago en el marco de la música de protesta contra el conflicto asiático o incluso hayan soslayado varias composiciones

los acontecimientos de Chicago y Kent State. Bradley, Douglas y Werner, Craig: We Gotta Get Out of this Place: The Soundtrack of the Vietnam War. Boston: University of Massachusetts Press, 2015.

5. K. Hillstrom y Laurie Hillstrom incluyen algunas canciones sobre el conflicto objeto de estudio: The Ballad of the Green Berets, Born in the U.S.A., Fortunate Son, Masters of War, Ohio, Okie from Muskogee y We Gotta Get out of This Place. Hillstrom, Kevin y Hillstrom, Laurie C.: The Vietnam Experience. A Concise Encyclopedia of American Literature, Songs and Films. Westport: Greenwood Press, 1998.

6. B. Franklin ofrece el análisis de tan solo cinco canciones: I-Feel-Like-I'm-Fixin'-to-Die Rag, The Ballad of the Green Berets, Obio, Fortunate Son y Born in the U.S.A. FrankLIn, Bruce: The Vietnam War In American Stories, Songs, And Poems. Boston: Bedford Books of St. Martin's Press, 1996.

7. En su obra, Andresen recopila 180 canciones, pero no incluye las obras referentes a los sucesos de Chicago en su selección y obvia varias composiciones referentes a las protestas de Kent State. ANDRESEn, Lee: Battle Notes. Music of the Vietnam War. Superior (Wisconsin): Savage Press, 2000.

8. En este sentido, resultan interesantes dos obras citadas con anterioridad: ARNOLD, Ben: op. cit., 1993; y ARNOLD, Ben: op. cit. 1991.

9. Lynskey analiza en la obra citada únicamente las siguientes canciones referentes a la Guerra de Vietnam: I-Feel-Like-I'm Fixin'-to-Die-Rag, Give Peace a Chance, War y Obio. A ellas puede añadirse Masters of War de Bob Dylan, que entendemos más como un alegato antimilitarista, toda vez que fue compuesta con anterioridad al incremento de presencia militar estadounidense acaecido en Vietnam desde 1965. Lynskey, Dorian: 33 Revolutions Per Minute. A History of Protest Songs, From Billie Holiday to Green Day. Nueva York: Harper Collins, 2011. 
referentes a los sucesos de Kent State. De este modo, un profundo análisis temático como el propuesto en estas líneas puede completar esta carencia.

\section{MÚSICA CONTRA UNA ATMÓSFERA OPRESIVA}

Los primeros años de la Guerra Fría impusieron un férreo conservadurismo en el panorama estadounidense. Esta tendencia acabó por generar el efecto contrario durante los años siguientes. Los jóvenes estadounidenses que habían nacido en la Gran Depresión y crecido durante el conflicto mundial, encontraron un ambiente asfixiante en los tiempos de la posguerra. Semejante atmósfera se caracterizaba por la ausencia de libertad individual en una vida cotidiana dominada por estructuras organizativas jerárquicas y cada vez más burocratizadas, tales como las grandes corporaciones o las universidades. Ante esta situación, dicha generación consideró que carecía de influencia sobre las políticas gubernamentales o incluso cotidianas. Sirvan como ejemplo al respecto las universidades que, nutridas por estos jóvenes, eran administradas por gestores procedentes de multinacionales que las sufragaban a cambio de investigaciones tecnológicos y militares: eran las denominadas multiversities ${ }^{10}$. Ello ensanchó la grieta entre rectores y jóvenes, los cuales se sentían ninguneados por un poder absoluto que imponía unas normas culturales que rechazaban. Esta oposición constituía la argamasa que reforzaba la conciencia grupal de esta generación y que, al mismo tiempo, le proporcionó una rebeldía contagiosa.

Esta generación constituyó una contracultura que, incubada en universidades como la de Columbia durante la década de 1950, rompió los paradigmas del conformismo y de la dirección social impuesta mediante el cuestionamiento del orden establecido. Durante los años siguientes, la contracultura concentró varios de los ideales del momento, los cuales incluían la armonía entre pueblos y el deseo de paz. Con estas aspiraciones, su aportación a la sociedad estadounidense es incuestionable: tolerancia, reformulación de los papeles de género y desafío a una autoridad que obstaculiza estos ideales ${ }^{11}$. Para potenciar estos objetivos, varios universitarios fundaron organizaciones como Students for a Democratic Society (s.D.s.), algunos de cuyos miembros redactaron el esclarecedor manifiesto de Port Huron en junio de 1962: «We are the people of this generation, bred in at least moderate comfort, housed in universities, looking uncomfortably to the world we inherit» ${ }^{12}$.

Sin embargo, esta generación halló un filón en dos cuestiones referentes a la política doméstica y a la exterior que obstaculizaban alcanzar su visión de la

10. Heinemann, Kenneth J.: Campus Wars. The Peace Movement at American State Universities in the Vietnam Era. Nueva York: New York University Press, 1993, pp. 13-14 y 20.

11. Fernández FerRer, Antonio: La canción folk norteamericana. Granada: Universidad de Granada, 2007, pp. 29-30.

12. Hayden, Tom: The Port Huron Statement, Nueva York: Students for a Democratic Society, 1964 , p. 3 
JUAN ANDRÉS GARCÍA MARTÍN

DE CHICAGO A KENT STATE: UN RETRATO MUSICAL DE LAS PROTESTAS

CONTRA LA GUERRA DE VIETNAM

sociedad estadounidense y del mundo. Por un lado, la lucha por los derechos civiles de los afroamericanos, la cual se vio acentuada durante la década de 1950 gracias a asociaciones como la N.A.A.C.P. Por otro lado, estos jóvenes cuestionaban la intervención norteamericana en la guerra de Vietnam como una amenaza no solo para la armonía entre naciones, sino para los propios valores de libertad que sustentaban el país.

Desde un punto de vista musical, estos reclamos cobraron interés para la música folk. Este género había adquirido una creciente presencia como forma de expresión y crítica de los grupos obreros en el contexto de pobreza y depresión que precedió a la guerra mundial. Al respecto, la tarea de recopilación musical realizada por el folklorista John A. Lomax y de composición por el cantautor Woody Guthrie resultó decisiva para la preservación y transmisión de este patrimonio. Los cantautores de música folk como Guthrie se sumergían en diversas músicas populares, al mismo tiempo que se identificaban con el pueblo llano y el obrero, compartiendo sus inquietudes y adoptando posicionamientos progresistas. A través de sus diferentes estilos y melodías, la música folk retrató las preocupaciones de la clase obrera, incluyendo entre su temática cuestiones de ámbito laboral como huelgas, derechos humanos o los conflictos bélicos del momento.

Durante los años siguientes, la semilla plantada por Lomax y Guthrie echó raíces. En el contexto de creciente persecución anticomunista, la música folk ejerció como vehículo de expresión y denuncia contra los valores establecidos a través de la canción de protesta. Este género, si bien ya existía con anterioridad, encontró una fuente de inspiración tanto en estas nuevas condiciones como en las acciones de protesta que inundarían la década de 1960. Su creciente expansión se produjo en universidades y en actos de protesta, pero también en festivales como el de Newport (Rhode Island), Greenwich Village (Nueva York) o North Beach (San Francisco). De este modo, la música folk y la canción de protesta caminaron juntas a la hora de denunciar las injusticias que impedían alcanzar los ideales establecidos por esta generación.

\section{LA MOVILIZACIÓN ANTIBÉLICA}

El limitado apoyo militar norteamericano proporcionado por el gobierno de John F. Kennedy a la República de Vietnam se vio incrementado con la llegada de Lyndon B. Johnson a la Casa Blanca en 1963. Esta escalada bélica vino acompañada de un goteo incesante de bajas estadounidenses. Por si fuera poco, una guerra en principio lejana no tardó en hacer acto de presencia en los hogares estadounidenses gracias a los nuevos medios de comunicación como la televisión y a voces críticas como el presentador Walter Cronkite. Ello proporcionó argumentos a quienes cuestionaban la idoneidad de esta intervención militar.

La oposición a la intervención estadounidense en Vietnam comenzó poco después de que el Congreso aprobara la Resolución del Golfo de Tonkín. En diciembre de 1964, tuvieron lugar las primeras manifestaciones que, imbuidas de un 


\section{JUAN ANDRÉS GARCÍA MARTÍN \\ DE CHICAGO A KENT STATE: UN RETRATO MUSICAL DE LAS PROTESTAS

carácter pacífico, trataban de imitar al Movimiento por los derechos civiles ${ }^{13}$. Su éxito fue inmediato y fueron coordinadas desde ciudades como Nueva York o San Francisco por agrupaciones pacifistas como la Student Peace Union (s.P.U.) o la War Resisters League (w.R.L.). Con el inicio de los bombardeos sobre Vietnam del Norte en febrero de 1965 y el envío de las primeras tropas al mes siguiente, se hizo evidente que la intervención militar no tendría un carácter limitado.

Como consecuencia, las universidades dieron un paso al frente y, en diferentes maneras, expresaron su opinión al respecto. Paradójicamente, ello se vio favorecido por los esfuerzos demócratas por extender las políticas educativas. Al necesitar nuevos docentes para hacer frente a esta ampliación, desde entonces, las universidades estimularon inconscientemente programas de humanidades, artes y ciencias sociales, los cuales albergaban a los docentes y alumnos más críticos con el conflicto ${ }^{14}$. A su vez, estos nutrían organizaciones como el s.D.s., que organizó varios seminarios -o teach-ins- en diversos campus con el objetivo de concienciar a la comunidad universitaria contra el conflicto: solamente el celebrado en 1965 en Ann Harbour, sede de la Universidad de Michigan, consiguió reunir a 3.000 estudiantes. La fiebre antibelicista pronto alcanzó la costa occidental del país, donde la semilla de la protesta juvenil había germinado desde hacía tiempo. En la universidad californiana de Berkeley, el Free-Speech Movement (F.S.M.) llevaba varios meses solicitando libertad académica y de expresión para los alumnos, por lo que no resultó difícil introducir un nuevo tema de debate en torno a una cuestión de actualidad. De hecho, la escalada bélica en Vietnam sirvió para conjurar a varias fuerzas sindicales, estudiantiles y pacifistas locales en una coalición antibelicista que, bajo el nombre de Vietnam Day Committee, no tardaría en adquirir una dimensión nacional.

De este modo, durante la primavera de 1965 surgieron todo tipo de iniciativas de protesta a lo largo y ancho del país. El 17 de abril de 1965, la s.D.C. demostró su capacidad de convocatoria entre los estudiantes a través de una manifestación en Washington D.C. contra los bombardeos. La cita fue culminada por un concierto antibélico en el que tomaron parte, entre otros cantautores, Judy Collins y Joan $\mathrm{Baez}^{15}$. Al día siguiente, más de 500 artistas constataron el rechazo de diferentes gremios creativos a la política exterior estadounidense en general y a la intervención en Vietnam en particular en un texto periodístico titulado "End Your Silence». Entre los abajofirmantes, se encontraban escritores, investigadores, compositores

13. Cortright, David: Peace: A History of Movements and Ideas. Cambridge: Cambridge University Press, 2008, p. 157; Tyner, James A. y Farmer, Mindy: Cambodia and Kent State. In the Aftermath of Nixon's Expansion of the Vietnam War. The Kent State University Press: Kent, 2020, p. 3.

14. Heinemann, Kenneth J.: op. cit., pp. 77-78.

15. Este concierto inauguró una serie de actos musicales que, durante los siguientes meses, expresaron su rechazo a la participación estadounidense en la Guerra de Vietnam. Al respecto, podemos citar el concierto celebrado en el Carnegie Hall de Nueva York el 24 de septiembre de 1965, al que asistieron más de 4.500 espectadores. 
JUAN ANDRÉS GARCÍA MARTÍN

DE CHICAGO A KENT STATE: UN RETRATO MUSICAL DE LAS PROTESTAS

CONTRA LA GUERRA DE VIETNAM

y cantautores que incluían a figuras como Allen Gingsberg, Philip Roth, Lawrence Ferlinghetti, Isaac Asimov, Morton Feldman y Joan Báez ${ }^{16}$.

Durante los siguientes años, el movimiento antibelicista rebasó la universidad. A los estudiantes, se añadieron reverendos, objetores de conciencia y madres de soldados fallecidos en combate, cuyas actividades incluían peticiones, campañas políticas, manifestaciones, actos de resistencia e incluso, acciones violentas ${ }^{17}$. Junto a todos estos colectivos, también cobraron cada vez mayor presencia y notoriedad los veteranos que habían participado en una contienda de la que habían vuelto desilusionados. Estos formaron organizaciones contrarias al conflicto como Vietnam Veterans Against the War y poco después, comenzaron a coordinarse con otras agrupaciones como el National Mobilization Committee to End the War in Vietnam (M.O.B.E.). El resultado fue una serie de demonstraciones de su fortaleza y capacidad de movilización a través de diversas manifestaciones. La primavera de 1966 fue testigo de congregaciones multitudinarias en ciudades como Nueva York, Boston, Chicago y San Francisco. El 4 de abril del año siguiente -justo un año antes de su asesinato-, Martin Luther King pronunció uno de sus discursos más antibelicistas en la Iglesia de Riverside (Nueva York) y diez días más tarde, la Gran Manzana reunió a 300.000 opositores a la contienda. Pocos meses después, en octubre, dos marchas expresaron su repulsa a la guerra frente al Pentágono y en el Memorial de Lincoln en Washington D.C.

En todas estas reuniones, el papel de artistas y cantautores contrarios al conflicto adquirió un papel creciente. Por ejemplo, el mencionado mitin en la explanada del Capitolio contó con la presencia de Phil Ochs. A estas alturas, varias voces habían expresado su disconformidad con la participación norteamericana en el conflicto y habían recogido el sentir del movimiento antibélico que recorría el país. Por ejemplo, Peter Seeger constató esta desazón cuando compuso Bring 'em Home (If You Love Your Uncle Sam, 1966) ${ }^{18}$, obra en la que el cantante neoyorkino se hizo eco de uno de los principales gritos de las manifestaciones antibelicistas. La canción, cuyas estrofas se dividen en dos partes a modo de pregunta y respuesta, se inspira en la estructura de los cantos de trabajo y espirituales afroamericanos. Con esta distribución, Seeger formula varias preguntas cuya respuesta es siempre la misma: la necesidad del regreso de los combatientes desde el lejano Vietnam so pretexto de reunirlos con sus familias. Seeger, además, incorpora a la letra otros argumentos del movimiento antibelicista, como por ejemplo el rechazo a situar la frontera ideológica de Estados Unidos en Vietnam ${ }^{19}$.

16. The New York Times, 18 de abril de 1965.

17. Anderson, David L.: The Columbia Guide to the Vietnam War, Nueva York, Columbia University Press, 2002, p. 65.

18. Broadside, n. ${ }^{\circ} 71$, junio de 1966, p. 6

19. Perone, James E.: op. cit., pp. 43-44. 


\section{JUAN ANDRÉS GARCÍA MARTÍN \\ DE CHICAGO A KENT STATE: UN RETRATO MUSICAL DE LAS PROTESTAS \\ CONTRA LA GUERRA DE VIETNAM}

Una línea similar fue adoptada por el grupo de folk-rock americano-canadiense Buffalo Springfield en For What It's Worth ${ }^{20}$, canción grabada como un sencillo en enero de 1967. Si bien en principio la obra se inspira en las revueltas protagonizadas por los jóvenes del barrio angelino de Sunset Strip ante la imposición de un toque de queda a finales del año anterior ${ }^{21}$, no es menos cierto que también recoge tanto la atmósfera de protesta antibélica y de insatisfacción por parte de los jóvenes norteamericanos, como la represión e imposición de normas consideradas obsoletas para aquellos, derivando ello en desconfianza hacia las fuerzas del $\operatorname{orden}^{22}$ :

There's something happening here

What it is ain't exactly clear

There's a man with a gun over there

Telling me I got to beware

I think it's time we stop, children, what's that sound

Everybody look what's going down

\section{ACCIÓN, REPRESIÓN, CANCIÓN}

\subsection{La renuncia de Johnson: del Tet a Chicago}

El 31 de enero de 1968, primer día del año nuevo vietnamita o Tet, el ejército de la República Democrática de Vietnam y la guerrilla del Vietcong lanzaron una ofensiva coordinada sobre varias ciudades survietnamitas. Si bien la ofensiva norvietnamita había fracasado, el impacto de aquella sobre la sociedad estadounidense supuso un jarro agua fría, ya que chocaba con las proclamas optimistas emitidas desde la Casa Blanca.

En este contexto, republicanos y demócratas iniciaron sendas elecciones primarias para definir a sus candidatos de cara a la cita electoral de noviembre de este año. Johnson, cuya popularidad se había reducido a un 35 \%, vio como Eugene McCarthy, un desconocido senador de Minnesota con un programa netamente pacifista, reunió el $42 \%$ de los votos en las elecciones primarias de New Hampshire $^{23}$. Si bien el presidente se impuso finalmente con un $49 \%$ de los votos, se trataba de una victoria pírrica que anticipaba un referéndum a su figura y a su

20. A partir de esta cita, aportamos siempre que ha sido posible el número de identificación de la canción consultada (fabricante-sello discográfico y referencia): ATco Records, 45-6459.

21. Los Angeles Times: "Closing of club ignited the "Sunset Strip riots" 5 de Agosto de 2007, por Cecilia Rasmussen.

22. Rolling Stone: "For What It's Worth': Inside Buffalo Springfield's Classic Protest Song", 30 de septiembre de 2020, por David Browne; Andresen, Lee: op. cit., p. 57.

23. El éxito inicial de la campaña de Eugene McCarthy se debió, en buena medida, al apoyo de jóvenes y estudiantes universitarios comprometidos con el movimiento antibélico. Para evitar su estigmatización y contar con mayor aprobación, accedieron a «asear» su aspecto físico. Para saber más, 
política exterior en cada uno de los próximos compromisos estatales. Por si fuera poco, Robert F. Kennedy, también se sumó a las elecciones primarias del partido desde posicionamientos críticos con la política exterior del presidente, lo que no hizo sino incrementar la fragmentación en el seno del propio Partido Demócrata. Fue entonces cuando un Johnson cada vez más aislado tomó una decisión inesperada: el 31 de marzo, el presidente ordenó detener los bombardeos sobre la República Democrática de Vietnam con vistas a iniciar negociaciones que condujeran a un alto el fuego y al mismo tiempo, anunció que no se presentaría a la reelección presidencial, lo que añadió incertidumbre a las elecciones primarias del partido.

Sin embargo, el abandono de Johnson no calmó unas aguas ya embravecidas. Cuatro días después, el reverendo Martin Luther King fue asesinado en Memphis (Tennessee), lo que desató una oleada de protestas de la comunidad afroamericana por todo el país. Para empeorar la situación, el pre-candidato Robert F. Kennedy murió asesinado a principios de junio, poco después de alzarse con la victoria en las elecciones primarias del Partido Demócrata en California. La pugna demócrata por la nominación presidencial quedaba desde entonces entre Eugene McCarthy y el vicepresidente Hubert Humphrey.

Desde este momento, la Guerra de Vietnam se convirtió en el tema dominante en la campaña electoral. La Convención Republicana celebrada en Miami a principios de agosto se decantó por Richard M. Nixon, quien ensalzó la gestión republicana para acabar con la Guerra de Corea años atrás ${ }^{24}$ y formuló dos promesas con las que pretendía atraer al voto conservador y moderado, aunque sin compromisos específicos al respecto: paz con honor en lo referente al conflicto vietnamita y «ley y orden» en lo tangente a los disturbios que sacudían el país.

Por su parte, los demócratas presentaban diferencias más profundas. Mientras que McCarthy se mostraba férreamente partidario de abandonar la contienda, Humphrey todavía defendía la participación en aquella. Finalmente, la Convención del Partido Demócrata celebrada en Chicago entre los días 26 y 29 de agosto se decantó por Humphrey, pero a un coste terrible. La reunión se vio no solo afectada por la profunda división que sacudía al partido en lo referente a la cuestión bélica, sino también por las protestas que tuvieron lugar en los exteriores del International Amphitheatre de la Ciudad del Viento. En previsión de éstas, el alcalde de la ciudad, el demócrata Richard J. Daley, había reforzado a la policía de Chicago con miles de efectivos de la Guardia Nacional, FBI y Servicio Secreto. Cuando los manifestantes antibelicistas convocados por la S.D.S., el M.O.B.E. y el Youth International Party se reunieron en los alrededores del edificio que albergaba la Convención Demócrata, Daley, quien ya se había mostrado inflexible durante la represión de las revueltas que siguieron al asesinato de Martin Luther King, dio órdenes taxativas

se recomienda la lectura de: Rising, George: Clean for Gene: Eugene McCarthy's 1968 Presidential Campaign. University of Arizona: Tucson, 1997.

24. Greenstein, Fred I.: The Presidential Difference. Leadership Style from FDR to Barack Obama. Princeton: Princeton University Press, 1998, p. 109. 
para desalojarlos a través del uso de la fuerza. Ante esta situación, los manifestantes entonaron "the whole world is watching», en clara alusión a la composición de Bob Dylan $^{25}$. Semejantes acciones fueron denunciadas por algunos asistentes a la Convención, como por ejemplo Abraham Ribicoff, senador demócrata de Connecticut, quien las definió como «tácticas propias de la Gestapo» ${ }^{26}$. Mientras tanto, los manifestantes, expulsados de los alrededores de la Convención, se dirigieron al Hotel Hilton, lugar de reunión de los delegados demócratas, donde nuevamente fueron disueltos por la policía, que no dudó en utilizar gases lacrimógenos. De este modo y después de varias noches de violencia, la victoria de Humphrey quedó eclipsada por cientos de detenciones y heridos, tanto entre los manifestantes como entre las fuerzas del orden ${ }^{27}$.

Junto a los candidatos de los dos partidos mayoritarios, hizo también acto de presencia George Wallace como cabeza del Partido Independiente Americano. Wallace, gobernador demócrata y segregacionista de Alabama, se presentó con un programa que prometía una mayor contundencia que Nixon en la cuestión del orden social y concluir victoriosamente la intervención en Vietnam. Finalmente, la cita electoral de noviembre de 1968 se saldó con la victoria de Richard Nixon por un estrecho margen. Wallace, por su parte, rebañó 10 millones de votos y 5 estados del Sur Profundo, suficiente para privar de la victoria a Humphrey ${ }^{28}$.

Los tumultuosos acontecimientos de 1968 no tardaron en quedar reflejados en varias composiciones que expresaron, de diferentes modos, tanto el deseo de abandonar el sudeste asiático como el rechazo a la intervención y represión policial contra los manifestantes antibélicos en Chicago. Aunque muchos historiadores han olvidado incluir las canciones referentes a las protestas en la Convención Demócrata entre las referentes al conflicto de Vietnam y al movimiento antibélico, lo cierto es que estas manifestaciones eran en gran medida la expresión del rechazo al conflicto. Al ser por lo tanto el vínculo entre ambas innegable, desde este texto creemos acertado analizar las obras referentes a aquellas jornadas.

Una de las primeras composiciones en plasmar estos eventos fue Oh, Chicago Town. La letra de esta canción fue escrita inmediatamente después de la Convención Demócrata por Mike Sherker y Wolf Lowenthal, quienes reciclaron para la ocasión la melodía de la obra Strawberry $\operatorname{Roan}^{29}$. En ella, el dúo denunciaba la violencia

25. Esta frase forma parte de la obra When the Ships Come In, compuesta por Bob Dylan en 1963 A pesar de esta alusión, no se han encontrado composiciones del cantautor de Minnesota en referencia a los sucesos de Chicago. TAylor, Jeff y Israelson, Chad: The Political World of Bob Dylan. Freedom, Justice, Power and Sin. Nueva York: Palgrave McMillan, 2015, p. 76.

26. Edy, Jill A.: Troubled Pasts. News and the Collective Memory of Social Unrest. Filadelfia: Temple University Press, 2006, pp. 43-58.

27. Farber, David: Chicago '68. Chicago: University of Chicago Press, 1988, pp. 165-207.

28. Schumacher, Michael: The Contest. The 1968 Election and the War for America's Soul. Minneapolis: University of Minneapolis Press, 2018, p. 464.

29. Esta obra es una canción escrita por el cowboy Curley Fletcher y publicada en 1915. Broadside, n. ${ }^{\circ}$ 94, agosto-septiembre de 1968, p. 3. 
JUAN ANDRÉS GARCÍA MARTÍN

DE CHICAGO A KENT STATE: UN RETRATO MUSICAL DE LAS PROTESTAS

CONTRA LA GUERRA DE VIETNAM

policial contra los manifestantes reunidos en Chicago, a los que descargaban de toda culpabilidad. Según estos autores, los manifestantes únicamente habrían provocado a la policía a través de sus sonrisas. Las fuerzas del orden, por su parte, habrían actuado con extrema dureza contra los manifestantes en base a unos estereotipos grupales tales como las melenas y los sucios ropajes.

La senda iniciada por estos dos compositores fue seguida por Phil Ochs, quien había sido testigo directo de la represión a los manifestantes. Como consecuencia, el cantautor tejano cayó en una profunda depresión durante los meses siguientes, llegando a declarar en una entrevista que "Chicago fue la muerte de la democracia en Estados Unidos» ${ }^{30}$. A pesar de ello, Ochs publicó en 1969 su sexto álbum con el título Rehearsals for Retirement ${ }^{31}$. En él, incluyó dos piezas con las que expresaba de manera explícita su repulsa a lo sucedido el año anterior: Where Were You in Chicago y William Butler Yeats Visits Lincoln Park and Escapes Unscathed. La primera de estas obras está compuesta por una breve estrofa en la que Ochs lanza al oyente una pregunta con la que mueve las conciencias de aquellos que no estuvieron presentes en Chicago:

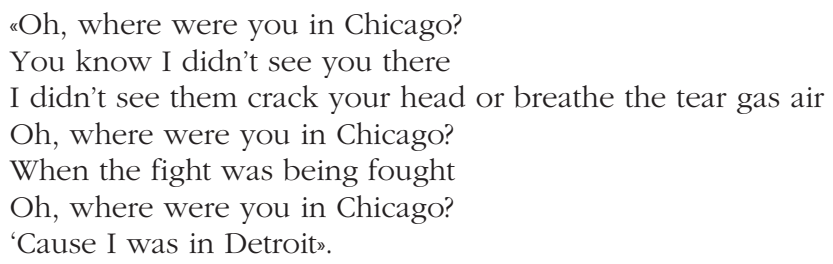

Por su parte, en William Butler Yeats Visits Lincoln Park and Escapes Unscathed, el cantante de El Paso coloca al poeta nacionalista irlandés homónimo como protagonista de una narración en la que este último visitaría Chicago y lograría escapar indemne de la represión. Tal y como sugiere Eliot $^{32}$, una lectura detallada de los contenidos de este álbum nos permite señalar que, para Ochs, los Estados Unidos transitaban de una democracia hacia una dictadura y la represión a los manifestantes, entendida como un atentado contra la libertad de expresión, sería tan solo una evidencia más de tal regresión.

Al mismo tiempo y aunque no constituye una obra crítica como tal, sino una pieza que se inspira en los acontecimientos de finales de agosto de 1968, el jazzista Charlie Haden publicó Circus '68, '69 (Liberation Music Orchestra, 1969) 33. Se trata de una composición instrumental en la que Haden intercala música y marchas

30. Schumacher, Michael: There but for Fortune. The Life of Phil Ochs. Nueva York: Hyperion, 1996, pp. 200-205.

31. A\&M Records \# SP 4181.

32. Eliot, Marc: Phil Ochs. Death of a Rebel. Nueva York: Omnibus Press, 1990, pp. 167-168.

33. Impulse! \# AS-9183. 


\section{JUAN ANDRÉS GARCÍA MARTÍN \\ DE CHICAGO A KENT STATE: UN RETRATO MUSICAL DE LAS PROTESTAS \\ CONTRA LA GUERRA DE VIETNAM}

electorales con un caos melódico e instrumentación a modo de silbatos policiales que, en su conjunto, rememora a las protestas y la consiguiente violencia policial.

Un año después, The Doors compuso Peace Frog (1970) como parte de su álbum Morrison Hotel ${ }^{34}$. En esta canción, la banda californiana expuso unos versos con los que recordaba las heridas de los manifestantes con el fin de expresar su oposición a la represión policial:

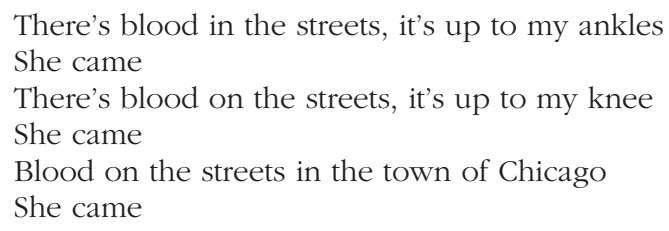

Los sucesos de Chicago se convirtieron paulatinamente en un tema de inspiración constante durante los meses siguientes. A pesar de que varios artistas hicieron una escueta mención en sus composiciones, podemos constatar su repulsa a lo acaecido durante la Convención Demócrata en las calles de Chicago. Así, por ejemplo, Barbara Dane publicó Bring Them Home (FTA! Songs of the GI Resistance, $1970)^{35}$, obra en la que la cantautora detroitina retomó la melodía, título y parte de los contenidos líricos trazados por Phil Ochs unos años atrás y los readaptó a los sucesos del verano de 1968, incluyendo una breve alusión a las manifestaciones y a la posterior represión («In Chicago or Vietnam, They're trying' to get us to be the man»). En segundo lugar, Larry Norman hizo lo propio en Peace, Pollution, Revolution (1972), pieza en la que se situó como participante tanto de las marchas sobre Washington como en Chicago, con el objetivo de denunciar la violencia de los hechos desde una perspectiva dramática ${ }^{36}$. Por último, Holly Near también compuso gI Movement (1974) ${ }^{37}$, canción en la que introdujo una breve referencia a los hechos que nos ocupan: "some landed in Chicago... but wherever they go they see a horror show». A pesar de que la participación estadounidense en Vietnam ya había concluido y el movimiento pacifista se había disuelto en el momento de la publicación de esta obra, la calificación de aquellas jornadas como un «espectáculo horrendo" posiciona a la activista y cantautora californiana en contra la guerra y de la represión que el movimiento antibélico había experimentado.

Sin embargo, el suceso que inspiró un mayor número de composiciones fue la detención y juicio de varios activistas y pacifistas durante las manifestaciones, siendo especialmente relevante el proceso judicial contra el grupo denominado como "Los ocho de Chicago" -Chicago Eight-: Abbie Hoffman, Jerry Rubin, David Dellinger, Tom Hayden, Rennie Davis, John Froines, Lee Weiner y Bobby Seale. En

\footnotetext{
34. Elektra - PRCD 947.

35. Paredon Records (\# P-1003).

36. MGM Records \# 2006105.

37. Redwood Records \# RRS 3800.
} 
JUAN ANDRÉS GARCÍA MARTÍN

DE CHICAGO A KENT STATE: UN RETRATO MUSICAL DE LAS PROTESTAS

CONTRA LA GUERRA DE VIETNAM

marzo de 1969, estos ocho manifestantes fueron acusados ante un gran jurado de conspiración e incitación a los disturbios. En otras palabras, se les responsabilizaba de los altercados que tuvieron lugar de manera paralela a la Convención Demócrata. El posterior juicio no fue precisamente tranquilo. La cantautora Judy Collins, testigo para la ocasión, trató de interpretar Where Have All the Flowers Gone, lo que le valió la amonestación del juez ${ }^{38}$. Por su parte, uno de los juzgados, Bobby Seale, miembro del Partido de los Panteras Negras, profirió diversas quejas contra el juez Julius Hoffman, por lo que éste ordenó amordazar al activista durante las sesiones. Finalmente, el magistrado separó a Seale del caso y lo sentenció a cuatro años de cárcel por desacato al tribunal, con lo que "Los ocho de Chicago" se convirtieron en "Los siete de Chicago"-Chicago Seven-.

Semejante desenlace no tardó en ser aprovechado por diferentes cantautores, que de manera inquebrantable se posicionaron de parte de los acusados en defensa de la libertad de expresión. Curiosamente, uno de los primeros en protestar contra el juicio a los manifestantes fue Abbie Hoffman, uno de los encausados. Este activista y cofundador del Partido Internacional de la Juventud publicó el álbum Wake Up America. ${ }^{39}$, en el que incluyó las piezas The Drug Company y Chicago. En la primera, Hoffman centró sus críticas en el alcalde Daley y el presidente Lyndon B. Johnson como responsables de la represión y de la situación que atravesaba el país a través de la siguiente estrofa: "we came to Chicago... there isn't a court in this country where we could have put Mayor Richard Daley, and L.B.J.». Por su parte, Chicago es una canción cómica y declamada de siete minutos de duración en la que contrapone los efectivos militares a los manifestantes, entre los cuales se incluye. Sin embargo, la parte más interesante corresponde a la enumeración de los días de encarcelamiento recibidos por sus desprecios al tribunal, ya que con ello expresa su desprecio por las instituciones estadounidenses y su funcionamiento:

\begin{abstract}
You should have seen that jury, that was some audience To play to... I got 28 days for contempt for laughing I got 14 for smiling, and I got 2 for throwing kisses at The jury... so I get up on the witness stand... the guy Says, you written any books, well I wrote this book Called "Fuck the System»... their heads were shaking Like windmills... our whole defense was geared around Giving the judge a heart-attack, there was no way of Beating the charge... we bombed in Chicago...
\end{abstract}

Junto a estas composiciones, John Chatman, más conocido como Memphis Slim, publicó la obra de jazz Chicago Seven (Blue Memphis, 1970) ${ }^{40}$. Acompañado

38. Coluns, Judy: Sweet Judy Blue Eyes. My Life in Music. Nueva York: Random House, 2011, pp. 341-343.

39. Big Toe Records \# 1 .

40. Warner Bros. Records \# WS 7500. 


\section{JUAN ANDRÉS GARCÍA MARTÍN \\ DE CHICAGO A KENT STATE: UN RETRATO MUSICAL DE LAS PROTESTAS CONTRA LA GUERRA DE VIETNAM}

por la guitarra de Peter Green, el pianista de Tennessee incorporó la denuncia racial a la cuestión al enunciar que el excesivo interés suscitado por el juicio no era sino el resultado de la condición de blancos de la mayoría de los acusados:

Everybody is talking about Chicago Seven

Four dead in Ohio, that makes eleven ${ }^{41}$

Nobody seems worried about all the black

Blood spilled, they'd begun to take notice.

Dicho de otro modo, Chatman sostiene que, de haber sido afroamericanos la totalidad de los encausados, el juicio no habría tenido semejante repercusión. A través de este argumento, el jazzista criticaba las desigualdades que todavía padecían los afroamericanos en Estados Unidos. Para clausurar 1970, The Lumpen, una agrupación musical forjada al calor del Partido de los Panteras Negras e integrada por Bill Calhoun, Clark Bailey y James Mott, fueron los siguientes en denunciar el juicio y encarcelamiento de Seale. En su obra funk Free Bobby Now (No More, $1970)^{42}$, la formación californiana introdujo la desigualdad racial como argumento de defensa del encausado:

He walked the streets and carried the gun To save his people and family, from those Who've killed us for four hundred years We say, Bobby must be set tree, Bobby

Con estas palabras, The Lumpen solicitaba la liberación de Seale con el siguiente argumento: si Seale se encontraba armado en el momento de su detención, ello se debía únicamente a la indefensión de los afroamericanos y a la larga tradición de abusos padecidos por esta comunidad. Poco después, esto es, en noviembre de 1970, fue Laura Nyro quien rindió homenaje a Bobby Seale en su álbum Christmas and the Beads of Sweat. En él, la cantautora neoyorkina incluyó Christmas in My Soul ${ }^{43}$, obra crítica con la participación norteamericana en Vietnam, pero también con el juicio a los "Siete de Chicago" y el encarcelamiento del miembro de los Panteras Negros, como demuestra la siguiente estrofa: «Black Panther brothers bound in jail... Chicago Seven and the justice scale».

Por su parte, Graham Nash publicó Chicago -obra también referenciada como We Can Change the World- (Songs for Beginners, 1971) ${ }^{44}$. Con esta pieza, el cantante británico expresó su solidaridad con Bobby Seale, pues cuestiona cómo se

41. La mención al estado de Ohio es una referencia a las protestas y masacre de estudiantes acaecida en la Universidad de Kent State en mayo de 1970, un año antes de la composición de esta canción. Estos hechos serán debidamente tratados en el siguiente epígrafe.

42. \# Black Panther Party-4501.

43. Columbia Records \# KC 30259.

44. Atlantic \# SD-7204. 
JUAN ANDRÉS GARCÍA MARTÍN

DE CHICAGO A KENT STATE: UN RETRATO MUSICAL DE LAS PROTESTAS

CONTRA LA GUERRA DE VIETNAM

puede llegar a amordazar y encadenar a la silla a un acusado durante un juicio en la tierra de las libertades. De este modo, Nash rechaza la actuación del juez Hoffman y la encuentra contraria a los valores de libertad con los que identifica al país, por cuanto es un ataque directo contra la Primera Enmienda:

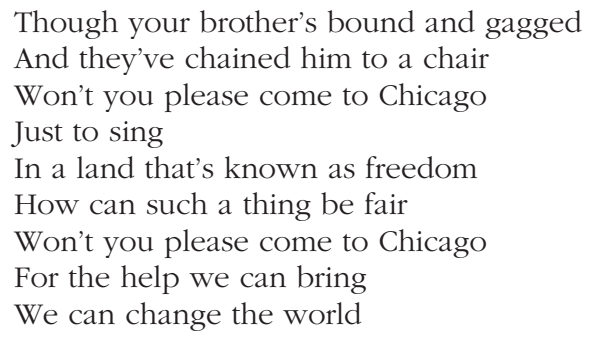

Un año después, David Peel \& the Lower East Side publicaron The Chicago Conspiracy (The Pope Smokes Dope, 1972) ${ }^{45}$, obra en la que la banda neoyorkina criticó al Partido y Convención Demócrata por ser una reunión artificial sin intención de hacer progresar a la sociedad estadounidense ("The Democrats convention was society's invention, To change our generation was one of their intentions»). Sin embargo, el peor parado de esta diatriba fue el alcalde Daley ("Mayor Daley made this place a city of disgrace»), a quien responsabilizaron de la represión.

La última de las composiciones en mencionar las protestas de Chicago fue elaborada por Brian Jackson y Gil Scott-Heron con H2O Gate Blues (Winter in America, 1974). En esta ocasión, nos encontramos ante una ácida poesía cantada y heterogénea temáticamente en tanto que realiza un recorrido por la actualidad sociopolítica del país. En ella, los autores incluyen ataques a la ya finalizada contien$\mathrm{da}$, como se puede observar en las menciones a la masacre de civiles en Vietnam o a los bombardeos sobre Cambodia. Del mismo modo, el dúo Scott-Heron y Jackson también alude a otros asuntos domésticos tales como el escándalo Watergate, pero a la represión de las protestas antibélicas, evocando los sucesos de Chicago y el juicio a Bobby Seale como los episodios más funestos ${ }^{46}$.

\subsection{Los mártires de Kent State}

El año 1968 concluyó con la llegada de Richard Nixon a la Casa Blanca. El candidato republicano accedió a la presidencia con dos promesas bajo el brazo: «ley y orden» y "paz con honor». Con una, procuraba garantizar la seguridad y el

45. Apple Records \# SW 3391.

46. Durante los años siguientes, algunos artistas norteamericanos publicaron canciones que referenciaron las protestas de Chicago. Al quedar fuera del espacio temporal escrutado en el momento de su composición, solamente la mencionaremos por si fuera de interés del lector: Long Black Wall (Michael Jerling, 1983). 


\section{JUAN ANDRÉS GARCÍA MARTÍN \\ DE CHICAGO A KENT STATE: UN RETRATO MUSICAL DE LAS PROTESTAS

bienestar material de los estadounidenses después de la ajetreada década de 1960, mientras que, con la segunda, pretendía una retirada lo menos traumática posible de Vietnam. No obstante, la herencia recibida estaba envenenada. A principios de 1969, los ataques norvietnamitas provocaban 453 bajas semanales estadounidenses, cifra que duplicaba los números habituales, al mismo tiempo que no se producía ningún avance militar sustancial. Ante esta realidad y a fin de que los survietnamitas ocuparan paulatinamente el hueco dejado por los norteamericanos, Nixon ordenó dos repliegues de tropas del sudeste asiático: era la vietnamización del conflicto. El anuncio de la retirada fue bien recibido por los activistas y, sin embargo, las protestas no se detuvieron. La represión del movimiento antibélico era muy reciente y las protestas permitían mantener viva la llama que demandaba libertad de manifestación y de expresión ${ }^{47}$.

Sea como fuere, la tranquilidad duró poco. En noviembre de 1969 se supo que, en marzo del año anterior, un destacamento militar estadounidense al mando del teniente William Calley había perpetrado el asesinato de más de 300 civiles en la aldea de My Lai ${ }^{48}$. Los oficiales del contingente fueron acusados de encubrimiento, pero solo Calley fue hallado culpable, para ser posteriormente indultado por Nixon. Al mismo tiempo, la realidad indochina impuso unas nuevas necesidades militares desde la perspectiva del presidente. La caída del régimen de Norodom Sihanouk en Camboya y el creciente poder de los comunistas en la región impulsaron que Nixon diera luz verde no solo a operaciones militares en aquel país, sino también al bombardeo de las bases norvietnamitas en la zona. Todo ello parecía retornar a la casilla de salida de noviembre de 1968.

El debate sobre la presencia norteamericana en el sudeste asiático se recrudeció y se constató la división de la sociedad estadounidense al respecto, ya que un $55 \%$ de los norteamericanos consideraban la guerra un error ${ }^{49}$. Al mismo tiempo, las críticas arreciaron. Desde 1969, la guerra era cada vez más impopular y las protestas resultaban atronadoras ${ }^{50}$, tal y como acredita el Moratorium para acabar la Guerra que inundó de manifestaciones y seminarios el país en octubre de 1969. Por su parte, Nixon y los republicanos fueron fieles a lo prometido en su campaña electoral y se revelaron menos indulgentes que su predecesor demócrata ante estas

47. Tyner, James A. y Farmer, Mindy: op. cit., pp. 7-11.

48. Las ya mencionadas Wake Up (1969) y H2O Gate Blues (1974) también contienen breves referencias que denuncian estos hechos.

49. McAdam, Doug y SU, Yang: "Antiwar Protests and Congressional Voting, 1965- to 1973", American Sociological Review, 67 (5), 2002, pp. 697-699.

50. Schreiber, E. M.: "Opposition to the Vietnam war among American University Students and Faculty", The British Journal of Sociology, 24 (3), 1973, pp. 289-291. En estos momentos, dos de cada tres estudiantes aprobaban la desescalada en el sudeste asiático. La opinión de Schreiber es apoyada por Zinn, quien sitúa el clímax de la protesta universitaria en el curso académico 1969-1970 con 1.785 manifestaciones estudiantiles y la ocupación de 313 edificios educativos. Zinn, Howard: A People's History of the United States, Nueva York: Harper Collins, pp. 458-459. 
JUAN ANDRÉS GARCÍA MARTÍN

DE CHICAGO A KENT STATE: UN RETRATO MUSICAL DE LAS PROTESTAS

CONTRA LA GUERRA DE VIETNAM

expresiones, tratando de descabezar el movimiento antibelicista durante los meses siguientes ${ }^{51}$.

Varias composiciones habían dejado constancia de la crispación existente en los campus: The Lament of the Minor Dean, Hey Mr. Newsman o Mine Eyes Have Seen the Horror of the Coming of the Reds no criticaban tanto la guerra de Vietnam como ridiculizaban a los rectores universitarios, la prensa y el exagerado temor al comunismo respectivamente ${ }^{52}$. Pero al calor de la creciente tensión, el compositor neoyorkino Dickie Goodman lanzó On Campus (1969)53, una absurda sátira musical que ridiculizaba a los principales políticos del momento -Daley, Nixon, Reagan, Agnew o Wallace- y reflejaba los vaivenes que sacudían los recintos universitarios ${ }^{54}$. Otros como The Stooges, constataron el cénit de estas protestas en su obra 1969 (Real Cool Time, 1969). En ella, la banda de rock de Detroit elevó esta efervescencia y manifestaciones a la categoría de situación bélica a lo largo y ancho del país, tal y como demuestra la siguiente estrofa: «Well It's 1969, OK! War across the USA! 55 .

Mientras tanto, el verano de 1969 fue testigo del festival musical de Woodstock. Artistas como Joan Báez, Janis Joplin o Jimi Hendrix y grupos como The Who, Jefferson Airplane, Creedence Clearwater Revival, CSNY o Country Joe McDonald and The Fish desfilaron por los escenarios instalados en las cercanías de una granja de la localidad neoryokina de Bethel. La reunión recibió miles de visitantes que no tardaron en expresar su rechazo a la guerra de Vietnam, lo cual quedó acreditado en varias de las interpretaciones que tuvieron lugar. De entre todas ellas, mención especial merece la banda californiana liderada por Country Joe McDonald que, testigo directo de los sucesos de Chicago del año anterior, entonó conmovida una obra que se había convertido en alegato pacifista: I-Feel-Like-I'm-Fixin'-to-Die $\mathrm{Rag}^{56}$. El carácter antibélico del festival musical neoyorkino fue recreado en varias composiciones durante los meses siguientes. Por ejemplo, Joni Mitchell compuso Woodstock $^{57}$, pieza en la que la cantautora canadiense no sólo reflejó el camino hacia el festival, sino que soñaba con bombarderos convertidos en mariposas ${ }^{58}$. Por su parte, la cantante neoyorkina Melanie Safka reprodujo escenas conmovedoras

51. Grace, Thomas M.: Kent State. Death and Dissent in the Long Sixties. Amherst: University of Massachusetts Press, 2016, pp. 176-183 y 186. De nuevo, Howard Zinn aporta datos ilustrativos en este sentido: solamente en el primer semestre de 1969, fueron arrestados 3.652 estudiantes y 956 fueron suspendidos o expulsados de sus universidades. ZINN, Howard: op. cit., pp. 458-459.

52. White, David M.: Protest Songs in America. Westlake Village: Aware Press, 1972, pp. 132-135.

53. Cotique - C-158.

54. AnDRESEn, Lee: op. cit., pp. 48-49.

55. Lynskey, Dorian: op. cit., p. 160.

56. La obra había sido compuesta cuatro años atrás e invitaba de manera sarcástica a los padres a enviar a sus hijos a luchar en Vietnam. Lynskey, Dorian: op. cit. pp. 87-101.

57. LMM - 2701072. La obra alcanzó cierto éxito y fue reversionada en 1970 por la banda británica Matthew Southern Comfort.

58. LaING, Dave: "The three Woodstocks and the live music scene». En Bennett, Andy (ed.) Remembering Woodstock. Nueva York: Routledge, 2004, p. 3. 


\section{JUAN ANDRÉS GARCÍA MARTÍN \\ DE CHICAGO A KENT STATE: UN RETRATO MUSICAL DE LAS PROTESTAS

del musical a la luz de las velas en Candles in the Rain (Lay Down) ${ }^{59}$. Junto a ellas, el cantante norirlandés Van Morrison dedicó Old, Old Woodstock ${ }^{60}$ a los presentes y ausentes en el festival ${ }^{61}$.

En primavera del año siguiente y coincidiendo con las primeras incursiones estadounidenses sobre Camboya, una oleada de indignación recorrió los campus universitarios del país. En este sentido, una de las escuelas más activas fue Kent State (Ohio). Se trataba de un centro educativo que contaba con un afanado movimiento antibelicista que, aunque algo falto de organización y liderazgo, había logrado protagonizar varias protestas contrarias al conflicto, sin actuaciones especialmente violentas, dicho sea de paso. A pesar de ello, la propia Universidad había incrementado su vigilancia sobre el movimiento antibelicista, como acredita la expulsión del S.D.s. de la Universidad en 1969. Todo ello, en definitiva, no hacía sino añadir gasolina al fuego ${ }^{62}$.

En este contexto, el 1 de mayo de 1970 tuvo lugar una manifestación antibélica que concluyó con varios disturbios en la ciudad, a los que el campus universitario no fue ajeno. Ante el incremento del nerviosismo, el gobernador republicano James A. Rhodes proclamó que erradicaría a "los comunistas» del campus y envió a la Guardia Nacional al recinto universitario ${ }^{63}$. A su llegada, los manifestantes habían incendiado el centro de entrenamiento de oficiales en la Universidad. La situación, relativamente calmada durante los dos días siguientes, tuvo un final trágico cuando, al mediodía del 4 de mayo, varios miembros de la Guardia Nacional abrieron fuego contra los manifestantes. Durante un cuarto de minuto, trece estudiantes fueron abatidos, con un saldo de cuatro muertos y nueve heridos, algunos de los cuales ni siquiera formaban parte de las manifestaciones antibélicas ${ }^{64}$. La respuesta de la comunidad universitaria no tardó en llegar y, en palabras de David Cortright, un auténtico levantamiento de campus universitarios sacudió el país ${ }^{65}$ : hasta 4.350 .000 estudiantes de 1.350 centros universitarios se manifestaron ya no solo contra la escalada militar en Camboya, sino también por la libertad de manifestación, de expresión y contra la represión del movimiento antibelicista, llegando

59. Buddah Records - BUCS 22.016.

60. Polydor - 5374502 .

61. ANDRESEN, Lee: op. cit. p. 46.

62. Grace, Thomas M.: op. cit., pp. 174-176. Una exhaustiva explicación de las protestas acaecidas en Kent State entre 1969 y 1970 está disponible en la obra referenciada en esta nota (pp. 193-206).

63. En aquel momento, los movimientos antibélicos de varias universidades como Berkeley, Chicago, Michigan o Wisconsin se habían manifestado de manera violenta en algunas ocasiones, por lo que posiblemente Rhodes quería evitar situaciones similares. Heinemann, Kenneth J.: op. cit., pp. $129-130$ y 247

64. En los años siguiente, tuvo lugar una riada de juicios en los que padres, estudiantes y sus abogados fueron indemnizados con 675.000 dólares por parte del estado de Ohio. Gregory, Stanford W. Jr. y LEwIS, Jerry M.: «Symbols of Collective Memory: The Social Process of Memorializing May 4, 1970, at Kent State University», Symbolic Interaction, 11 (2), (Fall), 1988, pp. 221.

65. Cortright, David: op. cit., p. 162. 
a considerar como hermanos a los caídos en Ohio ${ }^{66}$. En California, epicentro del Movimiento por la Libertad de Expresión, el gobernador Ronald Reagan optó por cerrar los campus universitarios. La protesta tampoco escapó a universidades privadas como Columbia, Princeton o Notre Dame, que sufrieron huelgas de estudiantes ${ }^{67}$. En algunos casos, la revuelta adquirió tintes raciales, llegando los altercados a provocar víctimas mortales: en la Universidad de Jackson State (Misisipi), un centro históricamente para estudiantes negros, las protestas de un millar de estudiantes afroamericanos contra la guerra y la represión en Kent State fueron respondidas con dureza por la policía local, con un resultado final de dos estudiantes muer$\operatorname{tos}^{68}$. Ante la magnitud de los acontecimientos, 536 universidades se vieron obligadas a cerrar en todo el país.

De este modo, la intervención estadounidense en Camboya acarreó un incremento de tensión doméstica en Estados Unidos, así como una creciente represión de las protestas contra aquella, especialmente en ámbitos universitarios y en centros educativos afroamericanos ${ }^{69}$. Semejante situación no podía ser pasada por alto desde un punto de vista musical y durante los años siguientes, varios artistas recogieron estos acontecimientos desde diferentes perspectivas, dando lugar a una ingente producción.

Algunas formaciones lanzaron críticas generales a la represión contra las manifestaciones antibélicas. Fue el caso de Quicksilver Mesenger Service, una banda de rock psicodélico originaria de San Francisco que publicó la canción What About Me en un álbum homónimo $(1970)^{70}$. Escrita por Dino Valente, más conocido como Jessi Oris Farrow, la canción refleja el ambiente de protestas antibélicas, con una alusión a los sucesos de Kent State («if you stand up... be prepared to be shot down») que sirve para denunciar la violencia policial y alertar a los manifestantes. Otra formación californiana, The Beach Boys, también optó por una crítica general a la represión al movimiento antibélico que recorría las universidades estadounidenses, aunque sin emplear términos tan abstractos como Quicksilver Mesenger Service. En su canción Student Demonstration Time (Surf's up, 1971) ${ }^{71}$, la banda angelina expresó su repulsa contra la contención del movimiento antibélico estudiantil a través de la enunciación de los episodios de represión y violencia que

66. Hillstrom, Kevin y Hillstrom, Laurie C.: op. cit., p. 213.

67. Para una visión más pormenorizada de las consecuencias de los sucesos en Kent State, recomendamos la lectura de Broadhurst, Christopher J.: "We Didn’t Fire a Shot, We Didn't Burn a Building”: The Student Reaction at North Carolina State University to the Kent State Shootings, May 1970", The North Carolina Historical Review, 87 (3), 2010, pp. 283-289.

68. The New York Times, 16 de mayo de 1970, p. 1; Ferguson, Roderick B. We Demand. The University and Student Protests. Oakland: University of California Press, 2017, pp. 14-15; Biond, Martha: Black Revolution on Campus. Los Angeles: University of California, 2012, p. 161.

69. Biondi, Martha: op. cit., p. 167.

70. La canción What About Me fue publicada como parte de un álbum (Capitol Records \# ST.630) en diciembre de 1970, pero en febrero del año siguiente, la formación californiana publicó la obra, esta vez, como sencillo (Capitol Records \# 3046).

71. Brother Records \# RS 6453. 
JUAN ANDRÉS GARCÍA MARTÍN

DE CHICAGO A KENT STATE: UN RETRATO MUSICAL DE LAS PROTESTAS

CONTRA LA GUERRA DE VIETNAM

habían jalonado la geografía estadounidense -desde los disturbios de People's Park en Berkely hasta Jackson State, pasando por Kent State-. Ello les permitió, literalmente, elevar a mártires a los estudiantes fallecidos:

America was stunned on May 4, 1970

When rally turned to riot up at Kent State University

They said the students scared the Guard

Though the troops were battle dressed

Four martyrs earned a new degree

The Bachelor of Bullets.

Sin embargo, la mayoría de los artistas y grupos musicales que criticaron los sucesos de Kent State y Jackson State optaron por denunciar aspectos concretos en sus canciones, haciendo la protesta más visible. Un primer grupo de composiciones integra todas aquellas obras que denunciaron la actuación de la Guardia Nacional como excesiva. Eso hizo que se opusieran a las fuerzas del orden unos estudiantes cuyas protestas son definidas como pacíficas de manera generalizada, siendo por lo tanto obviada cualquier agresión o comportamiento violento por parte de estos. De este modo, estudiantes y manifestantes son identificados por igual como víctimas de la represión y en el caso de los cuatro fallecidos, estos son convertidos en mártires del movimiento antibélico.

En este sentido, Third Condition, una banda de rock de garaje de Daytona Beach (Florida), abrió la crítica con su obra Monday in May (A May Day of Hell) (1970). Más adelante retitulada como Monday in May (The Kent State Tragedy) ${ }^{72}$, esta canción criticaba la desproporcionada intervención armada contra estudiantes en un día de "humillación y vergüenza" para el país. Acto seguido, la revista Broadside publicó varias canciones que aludían a estos acontecimientos y colocaba a Nixon como máximo culpable con unas viñetas incendiarias. Algunas obras como College on the Hill (1970) de Lois Morton, contraponían la primavera como estación idílica con el uso de balas y gas lacrimógeno contra estudiantes. Al mismo tiempo, la revista aprovechó para relanzar la canción Me gustan los estudiantes (1967), de la cantautora chilena Violeta Parra ${ }^{73}$.

Por su parte, J. J. Light, más conocido artísticamente como James Stallings, capitaneó a la banda de rock tejana Sir Douglas Quintet en el lanzamiento del sencillo Kent State $(1970)^{74}$. Stallings empleó una línea de defensa de los estudiantes en la cual optó por situarse como narrador en primera persona y testigo directo de los acontecimientos. A través de este recurso, incrementó el dramatismo de la narración al contraponer a tranquilos estudiantes frente al ataque de la Guardia Nacional. Ante semejante acción, Stallings da un paso más y llega incluso a amenazar

72. Billboard, 15 de agosto de 1970. Sundi Records \# SR-6815.

73. Broadside, n. ${ }^{\circ} 107$, junio de 1970 , pp. 2 y 4.

74. Liberty Records, \# 15393 A. 
a unas autoridades a las que rechaza: «better stop pushing us around or we'll kick your brains out».

\section{Groadside \#108 \\ JULY AUGUST 1970 \\ $50 屯$}

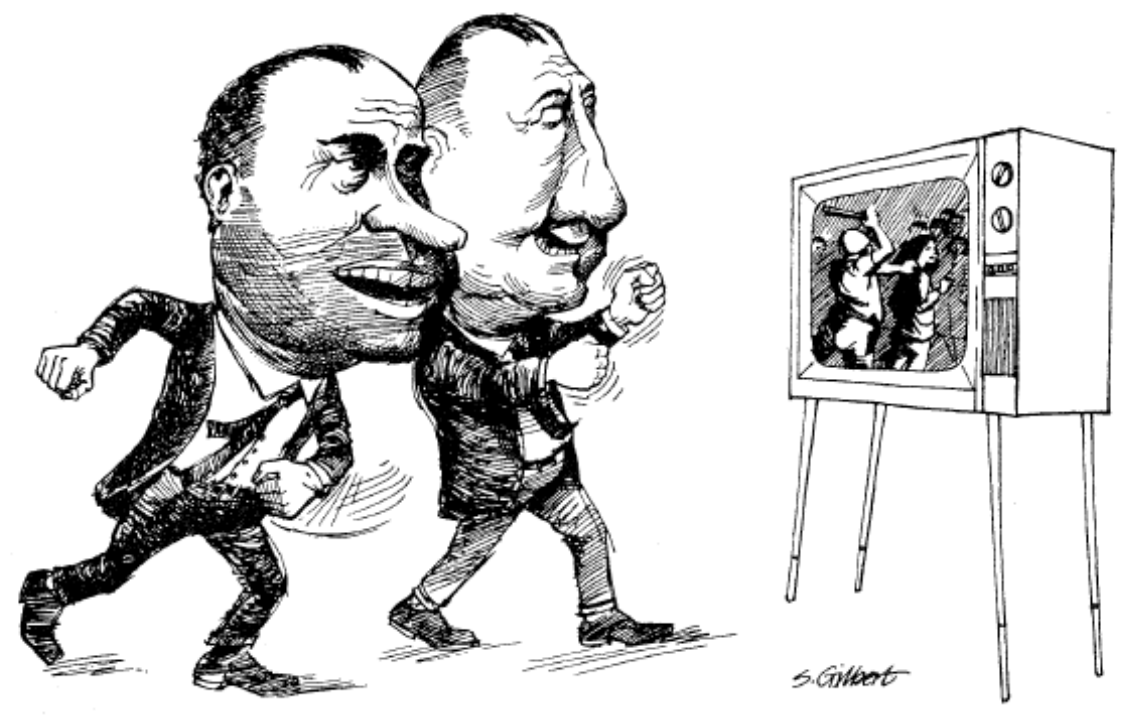

Broadside, n. ${ }^{\circ} 108$, julio-agosto de 1970, p. 1.

Poco después fue Pete Atkin quien dio un giro dramático al componer Driving Through Mythical America (1971) ${ }^{75}$. En esta pieza musical, el cantautor británico presenta los trágicos acontecimientos de una manera cinematográfica, ya que retrata a los estudiantes en total desconocimiento de marchar ante un pelotón de fusilamiento ("four students watched the soldiers load and aim... across the set and through the cardboard hills»), lo que permite recalcar la condición de víctimas de aquellos.

Un año más tarde, Harvey Andrews elaboró Hey! Sandy (Writer of Songs, $1972)^{76}$. Desde el mismo título, la canción está dedicada a Sandra Lee Scheuer, una de las cuatro víctimas mortales. A través de una descripción pormenorizada de los

75. Philips \# 6308070.

76. Cube Records \# Hifly 10. 
acontecimientos, el compositor británico no solo reconstruye el choque, sino que coloca al oyente en la escena y le hace empatizar con la estudiante, de la cual destaca su juventud e inocencia. Andrews no fue el único artista en dedicar de forma explícita una canción a los estudiantes fallecidos, como constata Truth Is Fallen $(1972)^{77}$, álbum instrumental compuesto por Dave Brubeck, en el que el pianista de jazz californiano introdujo la siguiente dedicatoria: "This music is dedicated to the slain students of Kent University and Mississippi State, and all other innocent victims caught in the cross-fire between repression and rebellion ${ }^{78}$.

Dentro de esta línea crítica, un número escaso pero significativo de artistas se decantó por incluir los nombres y apellidos de las víctimas en sus obras, lo que conducía a un ensalzamiento de unos jóvenes elevados a la categoría de mártires. Al respecto, podemos constatar al menos cuatro ejemplos. El dúo ocasional integrado por el trompetista de jazz Freddie Hubbard y el compositor de origen turco Ilhan Mimaroglu lanzó el álbum de jazz experimental Sing Me a Song of Songmy $(1971)^{79}$, en el cual encontramos varias referencias críticas al conflicto vietnamita tales como la masacre de My Lai o los sucesos de Kent State. Estos últimos quedaron recogidos en la canción What a Good Time for a Kent State, obra que comienza con una melodía para piano y saxofón que, a continuación, da paso a un coro que canta los nombres de los estudiantes asesinados y una frase lapidaria: "Words are better tan bullets». En segundo lugar, la cantante Barbara Dane, quien ya contaba con una larga trayectoria y compromiso antibélico, lanzó el álbum I Hate the Capitalist System (1973), en el que incluyó Kent State Massacre ${ }^{80}$. En esta pieza, la cantautora de la Ciudad del Motor contrapone a cuatro estudiantes que, en la flor de la vida, formaron parte de una marcha pacífica ("Allison Krause and Sandra Scheuer marched and sang a peaceful song, like Bill Schroeder and Jeffrey Miller») y se vieron sorprendidos en un ambiente de represión incomprensible ("the air was filled with tear gas, the troops did advance») en el que habrían dado su vida por aquellos que combatían en Vietnam, pero también por las libertades de aquellos que permanecían en suelo estadounidense. Por último, otra banda de rock de garaje llamada Evoloution lanzó Sandra, Allison, Jeffrey and Bill (Straws in the Wind, 1970), obra que incluye en el título el nombre de los estudiantes fallecidos, a los que coloca en consideración de mártires ${ }^{81}$.

Una línea similar a la anterior es ofrecida por Ruth Warrick, quien publicó la canción 41.000 Plus 4 (The Ballad of the Kent State Massacre) (1971). Warrick, actriz y cantante bien conocida por su papel en la película Ciudadano Kane, también dedica este poema recitado y acompañado de guitarra a los sangrientos

77. Atlantic \# SD 16060 .

78. Wilmeth, Tom: "A Previously Unpublished Interview with Dave Brubeck", recuperado en https://jazztimes.com/features/interviews/a-previously-unpublished-interview-with-dave-brubeck/ a [5 de septiembre de 2020].

79. Atlantic \# SD 1576.

80. Paredon Records \# P-1014.

81. Garlin Records \# 107. 
acontecimientos que tuvieron lugar en 1970: no solo las masacres de Kent State y Jackson State, sino también los disturbios raciales de Augusta (Georgia). El título de la obra hace referencia a los 41.000 norteamericanos muertos hasta la fecha en Vietnam -más adelante, la cifra se elevaría hasta 58.000-, a los que Warrick añade los cuatro estudiantes. Ello nos permite deducir que, si bien la cantante de Misuri incluye todos estos acontecimientos en su canción, el título y la mayor parte de la obra se centran en los sucesos de Kent State, ya que las víctimas mortales en Misisipi y Georgia son excluidas del encabezado y apenas mencionadas hasta la última estrofa. Por otra parte, la canción contrapone a los cuatro protagonistas, retratados como tranquilos paseantes en el campus de Ohio, con una Guardia Nacional excesivamente represora. Por último, Warrick coloca al presidente Nixon y al vicepresidente Spiro Agnew en el epicentro de la crítica al sembrar la duda sobre si el dúo ejecutivo habría sido quien diera la orden de disparar. Nixon, que unos días antes de estos sucesos había calificado a los manifestantes universitarios como "Vagabundos y radicales» ${ }^{82}$, es referenciado sin lugar a duda:

The president reviled, the bums, radicals, elite-snobs, Agnew smile, someone shouted they're blanks, only blanks,

don't get manic, splintered tres and Smahed cars meant real bullets caused panic.

La línea trazada por Warrick nos conduce a una segunda categorización temática que incluye a aquellas composiciones que centraron sus críticas en los líderes estadounidenses del momento: el presidente Richard Nixon y el vicepresidente Spiro Agnew. Entre estas obras, encontramos Jackson-Kent Blues, canción publicada por The Steve Miller Band como parte de su álbum Number 5 (1970) ${ }^{83}$. En esta melodía, el grupo de blues-rock californiano enarbola varios de los lemas del movimiento antibelicista, tales como "Give peace a chance», al mismo tiempo que observa una represión desmedida hacia la corriente antibélica en los trágicos sucesos de Ohio y Misisipi por parte del presidente Nixon, a quien describe como un gangster que emplea métodos inmorales.

El año 1970 también alumbró otras dos composiciones muy críticas con Richard Nixon y su vicepresidente. Por un lado, la formación de soul Coast publicó Why (A Peace Medley) ${ }^{84}$, en principio una canción antibélica que narra el alistamiento de un adolescente norteamericano para luchar en Vietnam. Sin embargo, una lectura más detallada nos indica que este grupo neoyorkino entremezcla pedazos de otras obras tales como Give Peace a Chance -John Lennon- y Helpless -Neil Young-, junto a una frase del vicepresidente Spiro Agnew: «Yippies, Hippies, Yahoos, Black Panthers, Lions and Tigers alike, I would swap the whole damn zoo

82. The New York Times, 2 de mayo de 1970, p. 1.

83. Capitol Records \# SKAO-436.

84. Massive Recods \# M-1001. 
for a single platoon of the kind of young Americans I saw in Vietnam ${ }^{85}$. La frase con la que el vicepresidente difamaba a los manifestantes como subversivos es utilizada en su contra por Coast, que contrapone al pulcro recluta con las víctimas y deja en evidencia la frialdad y escaso apego por la vida de los disidentes que Agnew había demostrado con estas palabras. Por otro lado, Barbara Dane también lanzó una diatriba contra el presidente Nixon en Hallelujah, I'm a Bum ${ }^{86}$, obra en la que se identificó con los estudiantes desde el mismo título. A lo largo de la composición, la cantante de Michigan criticó las palabras de Nixon estableciendo una correlación entre la burla presidencial y el desprecio por la vida exhibido en Kent State.

Por su parte, el tejano Don Sanders grabó la canción Kent State History Play $(1972)^{87}$, una de las composiciones más radicales sobre la cuestión. En ella, el músico de Houston colocó al vicepresidente Spiro Agnew en la diana. Este había culpabilizado a los manifestantes y les había señalado como violentos, justificando la represión sobre ellos incluso cuando algunas de las víctimas no guardaban relación ni participación directa con las protestas. Por ello, Sanders espera que Agnew reconociera su culpabilidad como miembro del poder ejecutivo («recognise his own guilt and he'll confess») y le invita a suicidarse en directo televisivo («kill himself in view of hungry TV cameras").

Para concluir esta segunda categoría, cabe citar Hey America, America (1973), obra grabada por el grupo Children of the Morning ${ }^{88}$. En esta ocasión, la banda liderada por Shel Shapiro centró sus ataques no tanto en el tándem Nixon-Agnew como en los argumentos que éstos habían manejado durante la crisis universitaria. De este modo, esta canción constituye un ejemplo de rechazo tanto a la tesis gubernamental de que la Guardia Nacional habría respondido en defensa propia, como al desenlace de los acontecimientos, ya que ningún guardia fue castigado por semejante ejercicio de fuerza. Al recurrir a estos planteamientos, el grupo de folk californiano potenció una imagen pacífica de los estudiantes.

Una tercera división temática puede incluir aquellas obras que se aproximaron a estos sucesos desde una perspectiva racial. En este sentido, Memphis Slim compuso Chicago Seven $(1971)^{89}$, obra ya referenciada en este texto. Si bien esta canción está dedicada al juicio de los siete activistas detenidos en la Convención Demócrata de Chicago en 1968, Chapman incluye referencias a otros acontecimientos como la masacre de Kent State con el objetivo de denunciar que el interés suscitado por ambos hechos se debía a la condición de blancos de la mayoría de

85. Life, 8 de mayo de 1970 , p. 69.

86. DANe, Barbara y SilBer, Irwin: FTA! Songs of the GI Resistance. Nueva York: Paredon Records, 1997. Paredon Records \# P-1003.

87. Sin número de registro de disco (H\&S Studios).

88. Hansa \# 12632 AT

89. Warner Bros Records \# 7500 . 
JUAN ANDRÉS GARCÍA MARTÍN

DE CHICAGO A KENT STATE: UN RETRATO MUSICAL DE LAS PROTESTAS

CONTRA LA GUERRA DE VIETNAM

los encausados y víctimas. Por su parte, The Last Poets ${ }^{90}$ publicó Black Soldier (Chastiment, 1972) ${ }^{91}$, canción que establece dos censuras: a la Guardia Nacional, como principal agente represor; y a los soldados afroamericanos que luchaban en Vietnam, en tanto que se habían involucrado en un conflicto ajeno, con lo que habían abandonado a su suerte a sus compatriotas para ser reprimidos en los campus universitarios. Finalmente, el dúo formado por Gil Scott-Heron y Brian Jackson lanzó H2O Gate Blues (Winter in America, 1974) ${ }^{92}$, poema en el que repasaban la actualidad estadounidense. Entre los hechos narrados, se incluían los sucesos de Kent State y Jackson State. Si bien Scott-Heron y Jackson no denunciaron ningún aspecto racista específico en estos sucesos, sí que lo hicieron en el resto de las cuestiones que regían el país: escuelas reticentes a finalizar la segregación o la presencia pública y participación política de segregacionistas como George Wallace, Frank Rizzo y Strom Thurmond.

Antes de concluir, debemos mencionar cuatro obras de difícil categorización. En primer lugar, Obio ${ }^{93}$, pieza grabada por el grupo de folk-rock Crosby, Stills, Nash \& Young (CSNY). La canción había sido escrita por Neil Young durante un breve retiro vacacional en California en el que observó el ejemplar de la revista Life dedicado a la masacre ${ }^{94}$. A través de este tema, el grupo californiano consigue recoger un sentimiento extendido en una sociedad conmocionada en aquel momento: en esta ocasión, Nixon había llegado demasiado lejos 95 .

Ahora bien, una lectura más detenida de la canción nos permite ver la fusión de dos versiones de Young -el activista antibélico y el músico de la contracultura- que dan rienda suelta a una serie de denuncias más concretas: además de criticar la gestión de la crisis y el autoritarismo de Nixon, Young plantea la idea de una juventud robada a unos estudiantes que simplemente observaban los acontecimientos ${ }^{96}$. Para ejecutar este planteamiento, CSNY alterna el punto de vista del pelotón de la Guardia Nacional con el de unos estudiantes que descubren un rosario de cadáveres al mismo tiempo que aquella marcha en su contra. Con este sacrificio, los estudiantes

90. Este grupo, originalmente fundado en el aniversario de la muerte de Malcolm X -19 de mayo de 1968-, más tarde agrupó a diferentes compositores y poetas que luchaban por la igualdad racial.

91. Blue Thumb Records \# BTS 39.

92. Strata-East Records \# SES-19742.

93. Atlantic \# 2740 .

94. En su autobiografía, Neil Young narra cómo la imagen de la estudiante Allison Krause tendida en el suelo en la portada de la revista Time impactó sobre el grupo. Sin embargo, tal y como corrigen Zimmer y Diltz, la memoria juega una mala pasada al compositor canadiense, ya que la revista Time no recogió semejante imagen en su ejemplar del 18 de mayo de 1970 (n. ${ }^{\circ}$ 95), sino que fue la revista Life. YOUNG, Neil: Waging Heavy Peace. A Hippie Dream. Nueva York: Penguin, 2012, pp. 245-246; ZIMMER, Dave y DILTZ, Henry: Crosby, Stills E Nash: The Biography. Boulder: Da Capo Press, 2000, p. 137.

95. Esta canción sería reversionada con una crítica feroz a Nixon por la banda de rock de garaje Maxima en Four Dead in Obio (GWS \# TRG-42) (1970). HILLSTROM, Kevin y HILLSTROM, Laurie C.: op. cit., pp. 213-215.

96. Broadside, n. ${ }^{\circ} 112$, marzo-abril de 1971, p. 3. 
JUAN ANDRÉS GARCÍA MARTÍN

DE CHICAGO A KENT STATE: UN RETRATO MUSICAL DE LAS PROTESTAS

CONTRA LA GUERRA DE VIETNAM

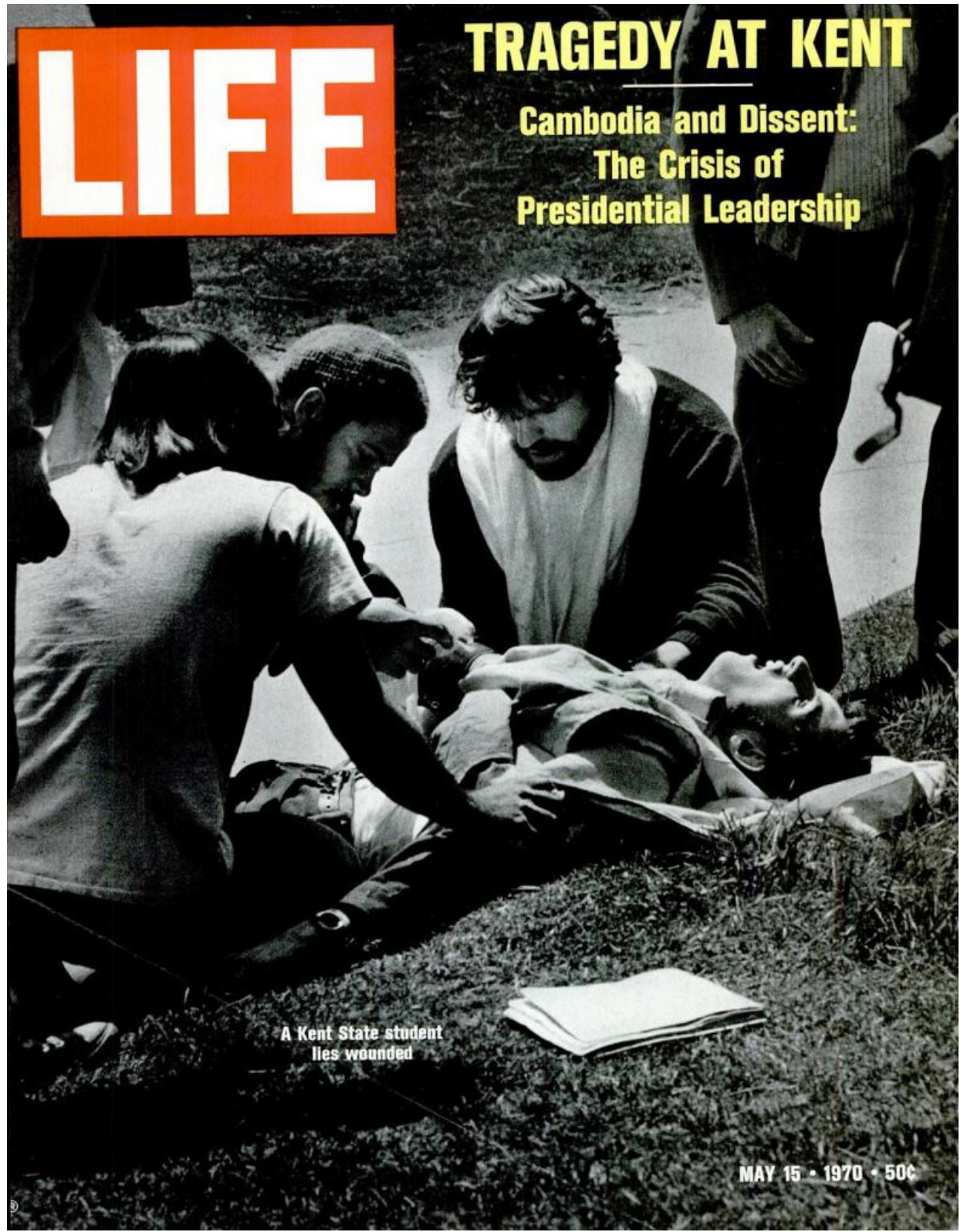

Portada de la revista Life. 15 de mayo de 1970. 
son elevados a la condición de mártires por la libertad y el movimiento antibélico ${ }^{97}$. El resultado fue una canción considerada como el mayor legado musical de la masacre $^{98}$. El compromiso de Young, por otra parte, no se detuvo en esta denuncia, ya que participó en un concierto en Cleveland en noviembre de 1970 para recaudar fondos para costear el proceso judicial abierto ${ }^{99}$ y en el que la interpretación de esta canción resultó estremecedora para muchos de los presentes ${ }^{100}$.

La influencia posterior de la obra de CSNY ha quedado constatada en la melodía Obio-Machine Gun (Givin' It Back, 1971) ${ }^{101}$, compuesta por The Isley Brothers. Para este alegato crítico con el conflicto y con la represión del movimiento antibélico, este grupo de música soul y funk de Cincinatti tomó prestado algunos contenidos líricos de la mencionada obra de Nash («I see tin soldier I hear them coming" y "Four dead in Ohio, Four Dead in Ohio») a los que añadió dramáticas descripciones referentes a balas, caos universitario y madres e hijos gritando de dolor, que no hicieron sino acentuar su carácter pacifista.

Una tercera obra de compleja categorización es It Could Have Been Me (A Live Album, 1974) ${ }^{102}$, escrita por Holly Near ${ }^{103}$. En ella, la cantante californiana efectúa un planteamiento semejante al realizado por Pete Atkin apenas tres años antes y esgrime la idea de unas balas anónimas disparadas por la Guardia Nacional, cuyos impactos supusieron víctimas mortales entre unos estudiantes que, con nombres y apellidos, podrían haber sido cualquier estadounidense. De este modo, Near traslada al oyente dentro de las manifestaciones y le conciencia tanto sobre la represión padecida como sobre el sacrificio de los estudiantes por los derechos y libertades colectivas.

En último lugar, no podemos ignorar Opera Files (1971), una pieza operística de 90 minutos de duración, escrita por el compositor egipcio-estadounidense Halim el-Dabh, quien había sido residente del campus de Kent State durante los

97. ANDRESEN, Lee: op. cit., pp. 58-59.

98. De acuerdo con algunos medios de comunicación como The Guardian, Ohio es la mejor canción de protesta nunca escrita. Halliwell, M.: Neil Young. American Traveller. Londres: Reaktion Books, 2015, pp. 72-74.

99. Grace, Thomas M.: op. cit., p. 249

100. Leone Keegan, una estudiante de la Universidad de Kent State presente en la masacre y en el concierto en Cleveland, definió la canción como «escalofriante». En Morrison, John y Morrison, Robert. K.: From Camelot to Kent State. The Sixties Experience in the Words of Those Who Lived It. Nueva York: Oxford University Press, 1987, p. 338.

101. SICP 2863.

102. Redwood Records \# 3700 .

103. Holly Near era a la sazón una de las activistas antibélicas más destacadas, como acredita su participación junto a actores como Jane Fonda y Donald Sutherland en varias manifestaciones pacifistas como el F.T.A. Tour (Free the Army, o incluso Fuck the Army), una suerte de gira de conciertos por cafés y restaurantes cercanos a bases militares llevado a cabo entre 1971 y 1972 como respuesta al tour On the Road to Vietnam, llevado a cabo por el comediante Bob Hope para elevar la moral de las tropas estadounidenses. Small, Melvin: Antiwarriors: The Vietnam War and the Battle for America's Hearts and Minds. Oxford: SR Books, 2004, p. 150; Ross, Steven J.: Hollywood Left and Right: How Movie Stars Shaped American Politics. Nueva York: Oxford University Press, 2011, pp. 237-238. 


\section{JUAN ANDRÉS GARCÍA MARTÍN \\ DE CHICAGO A KENT STATE: UN RETRATO MUSICAL DE LAS PROTESTAS \\ CONTRA LA GUERRA DE VIETNAM}

sucesos. La obra, que fue representada en Washington, Nueva York y en la propia Universidad de Ohio, constituye un alegato por la libertad de manifestación y una crítica a la intervención de la Guardia Nacional, tal y como el propio el-Dabh explica: "It's all about man's rights versus the need for social control» ${ }^{104}$.

\section{LOS OTROS AMERICANOS}

Mientras las universidades estadounidenses articulaban buena parte de la protesta contra la guerra de Vietnam, algunos sectores de la sociedad norteamericana observaban en ellas una excesiva radicalización. Por lo tanto, al mismo tiempo que proliferaban las expresiones pacifistas por toda la geografía estadounidense, también se fraguó un amplio movimiento favorable a la intervención norteamericana en el sudeste asiático. Apoyado por los grupos conservadores estadounidenses, este movimiento elaboró un discurso cada vez más agresivo contra los detractores de la contienda, denigrando a universitarios y sectores liberales, a quienes tildaban de antipatriotas por no apoyar una lucha en defensa de la democracia y libertad ${ }^{105}$. De este modo, Nueva York fue testigo de una marcha de 70.000 personas en la Quinta Avenida en apoyo de la guerra de Vietnam en mayo de 1967. En la primavera de 1970, varios miles de manifestantes se congregaron periódicamente durante dos semanas en Wall Street, intentando contrarrestar al movimiento antibélico que exhibía músculo por todo el país.

En consecuencia, no es de extrañar que el movimiento antibélico en general y las universidades en particular se convirtieran en objeto de crítica. Ahora bien, ¿qué músicos desarrollaron estos ataques? La respuesta la encontramos, principalmente, en la música country, un estilo que se había difundido a lo largo y ancho del país de la mano de la población sureña en tiempos de la Gran Depresión y el New Deal. En otras palabras, la diáspora de sureños empobrecidos y procedentes de zonas conservadoras como el Cinturón de la Biblia durante la década de 1930 permitió la difusión de este estilo musical en regiones tan lejanas como California o los Grandes Lagos.

A medida que avanzaba la década de 1960, cantantes como Marty Robbins, Johnnie Wright, Dave McEnery, Ernest Tubbs o Merle Haggard habían proporcionado argumentos a la lucha en Vietnam, así como denostado a los manifestantes antibélicos $^{106}$. En palabras de Bill C. Malone, muchas de estas canciones eran "pro-

104. The New York Times, "Kent State Composer Threads Tragedy Into Opera", 31 de mayo de 1971, por Donald Henahan.

105. SCAnlon, Sandra: The Pro-War Movement. Domestic Support for the Vietnam War and the Making of Modern American Conservatism. Amherst: University of Massachusetts Press, 2013, pp. 7-15.

106. García Martín, Juan A.: "La Guerra de Vietnam: una mirada a través de la canción protesta estadounidense», El Futuro del Pasado, 9, 2018, pp. 51-56. 
JUAN ANDRÉS GARCÍA MARTÍN

DE CHICAGO A KENT STATE: UN RETRATO MUSICAL DE LAS PROTESTAS

CONTRA LA GUERRA DE VIETNAM

testas contra los que protestan» ${ }^{107}$. Por lo tanto, los acontecimientos comprendidos en el trienio que transcurre entre 1968 y 1970 tampoco escaparon a esta tendencia.

Las manifestaciones y altercados que tuvieron lugar durante la Convención Demócrata de Chicago quedaron constatadas en dos canciones anti-protesta. Una de las primeras obras en este sentido fue Telling It Straight in '68 (1968) ${ }^{108}$, un sencillo lanzado por Jim Hartley and The Orange State Playboys. Se trata de una obra dividida en dos partes en la que el grupo de bluegrass de Florida -de ahí la referencia al Estado de las Naranjas en su nombre- se posicionaba electoralmente a favor de George Wallace, al mismo tiempo que calificaba como "comunistas» y «saqueadores" a los manifestantes, algo por lo que defendió la actuación policial y la figura del alcalde Daley. Tres años después, Warren Farren lanzó Chicago 7, obra compuesta como parte del librillo I've Got Love (1971) ${ }^{109}$. En ella, Farren atacó con contundencia a los manifestantes pero, sobre todo, a los siete juzgados, a los que definió en el estribillo de la siguiente manera:

Take the seven brothers of hate, Mark them so the country knows, they made a deal with Satan,

but a price tag on their soul.

Además, la crítica de Warren no se detenía ahí, ya que también acusaba a los siete procesados de haber acudido a Chicago con intención de causar problemas y mancillar la bandera de las barras y estrellas. Para finalizar, Farren contraponía a los Siete de Chicago con los soldados norteamericanos que combatían en Vietnam, los cuáles suponían un ejemplo para la nación. Junto a ellas, podemos constatar otra canción que, no obstante, escapa a la visión patriótica fomentada por la música country. Hacemos alusión a Walt Wilder y su obra Chicago's "7》" (Chicago's Old Town, 1970) ${ }^{110}$, en la que el cantautor de Oklahoma se posiciona junto a los protestantes, más no tanto para defender las proclamas antibélicas, sino como apología de la libertad de expresión.

Cuando de manera simultánea el ambiente de protesta se acentuó en los campus de todo el país, varios cantautores de música country también incorporaron la crítica de las universidades y de sus revoltosos estudiantes a sus composiciones, aunque sin menciones específicas a sucesos como los acaecidos en Kent State. Uno de los primeros en hacerlo fue Autry Inman, autor de Ballad of the Two Brothers en un álbum homónimo $(1968)^{111}$. En ella, el guitarrista de Alabama contrapone a dos hermanos, cada uno de los cuales lucha a su manera: Bud combate en Vietnam

107. Malone, Bill C. y Laird, Tracey E. W.: Country Music USA, Austin: University of Texas Press, 2018, pp. 375-376.

108. Orange \# W-1968.

109. Trip Universal Records \# T-67.

110. Phils Records \# 1025.

111. Epic BN 26428. 


\section{JUAN ANDRÉS GARCÍA MARTÍN \\ DE CHICAGO A KENT STATE: UN RETRATO MUSICAL DE LAS PROTESTAS

y Tommy protagoniza protestas en la universidad. Este último es caricaturizado como un joven problemático, voluble y barbudo que, además, exprime económicamente a sus padres. Se trata, de acuerdo con Inman, de un parásito que no hace sino contribuir a la derrota moral y política de la nación. Al ser las universidades uno de los epicentros de las protestas antibélicas, el profesorado queda igualmente caracterizado como peligrosos progresistas que utilizan su posición para lavar el cerebro a sus alumnos y utilizarlos como peones del comunismo ${ }^{112}$ :

Our economics professor assured us

That people get along

Just as well under communism

As they do under

Any other form of government.

Por lo tanto, la desconfianza en las universidades y su personal docente constituye una idea extendida entre quienes rechazaban el movimiento antibélico. Al respecto, sirve como ejemplo la obra de Harlan Howard, quien no había dudado en apoyar al movimiento favorable a la guerra en público, como acredita su participación en la marcha pro-bélica que tuvo lugar en Manhattan en mayo de 1970, en la cual se interpretaron varias de sus obras ${ }^{113}$. Un año después, este cantautor de Detroit compuso Mr. Professor, melodía incluida en el álbum To the Silent Majority, With Love (1971) ${ }^{114}$. Este es un libreto cuyo título se inspira en un discurso que Richard Nixon pronunció en vísperas de las elecciones de 1968 y con el que pedía el voto a aquellos norteamericanos amantes del orden y que constituían una mayoría poco ruidosa en comparación con los protestantes pacifistas ${ }^{115}$. Con la canción mencionada, Howard carga las tintas contra aquellos maestros que inducen a sus pupilos hacia el ateísmo, la resistencia al alistamiento y al desorden. Con ello, el cantante de Michigan retrata a las universidades como un semillero antibélico y extiende la sospecha sobre todo el cuerpo docente, al que considera instigador de las protestas.

Ahora bien, ¿estaban fundamentadas las críticas de Inman o Howard? La participación universitaria en la oposición a la Guerra de Vietnam resulta tan innegable como ruidosa, pero no debe ser magnificada. Los cantautores más conservadores tomaron como certeza la tendencia en la que navegaban los centros educativos del país y la elevaron al conjunto. Ello, no obstante, no concuerda por completo con la realidad. A finales de la década de 1960, dos de cada tres estudiantes aprobaban la desescalada, mientras que entre el personal docente universitario también existía

112. Perone, James E.: op. cit., pp. 96-97.

113. LyNSKEY, Dorian: op. cit., p. 171.

114. Nugget NRLP-105.

115. Discurso de aceptación a la nominación para candidato presidencial de Richard Nixon pronunciado el 8 de agosto de 1968: Flamm, Michael W.: Law and Order. Street Crime, Civil Unrest, and he Crisis of Liberalism in the 1960s. Nueva York: Columbia University Press, 2005, pp. 8 y 25. 
JUAN ANDRÉS GARCÍA MARTÍN

DE CHICAGO A KENT STATE: UN RETRATO MUSICAL DE LAS PROTESTAS

CONTRA LA GUERRA DE VIETNAM

un rechazo que se manifestaba en una amplia gama cromática: el $18 \%$ de los funcionarios de universidades defendían la retirada inmediata del sudeste asiático, mientras que un 33 \% pedía reducir la intervención armada siempre y cuando se previniera cualquier acceso comunista al poder. En esta línea, ni siquiera durante la participación del abiertamente pacifista Eugene McCarthy en las elecciones primarias del Partido Demócrata, apenas uno de cada cinco docentes se mostró favorable a la retirada inmediata de Vietnam ${ }^{116}$.

\section{CONClusiones}

El incremento de las protestas contra la participación estadounidense en la Guerra de Vietnam alcanzó su cénit entre 1968 y 1970 a través de acontecimientos tales como las manifestaciones en la Convención Demócrata de Chicago y las protestas universitarias de 1970. Estos sucesos acapararon la atención de medio centenar de obras musicales que han sido recogidas en este texto y que marcaron un antes y un después en los argumentos empleados por las composiciones de protesta. Con anterioridad a 1968, las primeras expresiones musicales que constataron las manifestaciones antibélicas y que apoyaron esta corriente de opinión fueron llevadas a cabo de manera abstracta y poco precisa. Por un lado, estas canciones mostraban su rechazo al alistamiento, recogían expresiones y lemas de las protestas y los plasmaban en títulos o en sus contenidos líricos. Por otro lado, evitaban referenciar protestas como las acaecidas en Washington o Nueva York de manera concreta, así como episodios sangrientos en los que los manifestantes hubieran encontrado la muerte.

Sin embargo, los trágicos eventos de verano de 1968 en la Convención Demócrata de Chicago fueron rápidamente incluidos en un repertorio musical que se multiplicó exponencialmente y evolucionó desde un punto de vista temático. Las protestas acaecidas durante la reunión del Partido Demócrata y la represión policial de los manifestantes pacifistas fueron objeto de denuncias específicas a partir de entonces. En concreto, la actuación del alcalde Daley y de las fuerzas del orden de la ciudad fueron censuradas con dureza por llevar a cabo un ejercicio de autoritarismo contra los derechos de libertad de expresión y manifestación. El posterior juicio a los líderes detenidos -los Siete de Chicago- acaparó la mayoría de composiciones críticas, las cuales impugnaban el procedimiento judicial y el amordazamiento de uno de los encausados durante la sesión. En consecuencia, la mayoría de estas obras solicitaban tanto la inmediata liberación de los activistas arrestados como la libertad de expresión de los manifestantes pacifistas.

Ahora bien, junto a estas diatribas, hubo una porción minoritaria pero significativa de composiciones que esgrimieron argumentos raciales. De este modo, grupos como The Lumpen o artistas como Memphis Slim criticaron la represión

116. Schreiber, E. M.: op. cit. pp. 291-292. 
a los líderes arrestados no tanto por su oposición al conflicto vietnamita sino por su condición afroamericana, en lo que a su juicio constituía un episodio más de racismo institucional que impediría progresar al país.

Las promesas electorales de paz social realizadas por Richard Nixon durante la campaña de 1968 quedaron en papel mojado con la intervención estadounidense en Camboya dos años después. Los bombardeos norteamericanos sobre esta región recrudecieron las protestas universitarias a lo largo y ancho del país, generando varias víctimas mortales en las universidades de Kent State y Jackson State. La producción musical de ambas protestas resulta dispar, en tanto que la mayoría de composiciones aluden a los sucesos de Ohio, relegando las protestas de la Universidad de Misisipi a un plano muy secundario.

Las canciones referentes a estos acontecimientos coinciden de manera abrumadora en su crítica a la actuación de la Guardia Nacional, que describen como excesiva y rechazan por atentar contra la libertad de reunión y de expresión. Ello establece una división entre represores y víctimas en la que, mientras los primeros son villanizados, los segundos son elevados a mártires de la causa antibélica, aun cuando algunos de ellos no formaban parte de las protestas. En este sentido, las canciones incorporan recursos líricos tales como una exhaustiva dramatización y descripción de los acontecimientos; un acercamiento e idealización de las figuras de los estudiantes represaliados, por ejemplo, incluyendo sus nombres en las letras; o, en sentido contrario, una caricaturización y demonización del presidente Richard Nixon y el vicepresidente Spiro Agnew, a quienes consideran instigadores del desastre, y de quienes rechazan las explicaciones y argumentos esgrimidos durante los días anteriores y posteriores a la crisis. Ello contrasta, por otra parte, con las escasas menciones al gobernador James A. Rhodes, responsable del envío de las fuerzas de seguridad en el caso de Kent State. Para cerrar este apartado, en el caso de la represión sobre estas dos universidades, existe escasez de argumentos raciales, pues los compositores tienden a entender las protestas como una reacción del conjunto de la comunidad universitaria, sin connotaciones de raza.

En su conjunto y desde un punto de vista programático, las canciones referentes a las protestas del movimiento antibélico no proponen soluciones ni un programa político concreto más allá del final de la participación militar estadounidense en el conflicto vietnamita; el retorno de los combatientes estadounidenses; y el fin de la represión del movimiento antibélico. Estas obras tampoco realizan propuestas para mejorar una democracia estadounidense de cuyo funcionamiento desconfían y cuyas injusticias denuncian. Por lo demás, un número reducido de composiciones plantea la paradoja implícita en esta represión: luchar por la libertad y democracia en Vietnam, mientras estos valores son limitados en Estados Unidos. Ahora bien, semejante desierto de represión solo se hace llevadero para los cantautores que protestan contra esta coyuntura en tanto que es el peaje a pagar para alcanzar un horizonte de libertad.

Por último, no debemos olvidar que la mayoría de estas composiciones se engloban dentro de la música folk, género revitalizado durante la década 1960. 
No obstante, conviene matizar que, a medida que avanzamos en esta década y penetramos en la de 1970, otros géneros tales como el rock, funk o la música psicodélica también tomaron parte de la protesta musical contra la intervención estadounidense en Vietnam y contra la represión del movimiento antibélico. Por lo tanto, estos estilos musicales no hicieron sino retratar la actualidad que atravesaba el país, añadiendo sus particulares perspectivas a través de diferentes argumentos que confirieron una visión poliédrica de la cuestión que hemos estudiado. 